\title{
Article \\ Big Data and Energy Security: Impacts on Private Companies, National Economies and Societies
}

\author{
Hossein Hassani ${ }^{1, *}$, Nadejda Komendantova ${ }^{2} \odot$, Daniel Kroos ${ }^{3}$, Stephan Unger ${ }^{4}$ and Mohammad Reza Yeganegi ${ }^{5}$ \\ 1 Research Institute of Energy Management and Planning, University of Tehran, Tehran 1417466191, Iran \\ 2 Advanced Systems Analysis Program, International Institute for Applied Systems Analysis (IIASA), \\ Schlossplatz 1, 2361 Laxenburg, Austria; komendan@iiasa.ac.at \\ 3 World Energy Council Austria, Brahmsplatz 3, 1040 Vienna, Austria; dkroos@bluewin.ch \\ 4 Department of Economics \& Business, Saint Anselm College, Saint Anselm Drive 100, \\ Manchester, NH 03102, USA; sunger@anselm.edu \\ 5 Department of Accounting, Islamic Azad University Central Tehran Branch, Tehran 1148963537, Iran; \\ m.yeganegi@iauctb.ac.ir \\ * Correspondence: hosseinhassani57@webster.edu
}

check for

updates

Citation: Hassani, H.;

Komendantova, N.; Kroos, D.; Unger, S.; Yeganegi, M.R. Big Data and Energy Security: Impacts on Private Companies, National Economies and Societies. IoT 2022, 3, 29-59. https:// doi.org/10.3390/iot3010002

Academic Editors:

Vijayakumar Varadarajan and

K. Kalaiselvi

Received: 30 October 2021

Accepted: 15 December 2021

Published: 23 December 2021

Publisher's Note: MDPI stays neutral with regard to jurisdictional claims in published maps and institutional affiliations.

Copyright: (C) 2021 by the authors. Licensee MDPI, Basel, Switzerland. This article is an open access article distributed under the terms and conditions of the Creative Commons Attribution (CC BY) license (https:// creativecommons.org/licenses/by/ $4.0 /)$.

\begin{abstract}
The importance of energy security for the successful functioning of private companies, national economies, and the overall society cannot be underestimated. Energy is a critical infrastructure for any modern society, and its reliable functioning is essential for all economic sectors and for the well-being of everybody. Uncertainty in terms of the availability of information, namely reliable data to make predictions and to plan for investment as well as for other actions of stakeholders in the energy markets is one of the factors with the highest influence on energy security. This uncertainty can be connected with many factors, such as the availability of reliable data or actions of stakeholders themselves. For example, the recent outbreak of the COVID-19 pandemic revealed negative impacts of uncertainty on decision-making processes and markets. At the time point when the market participants started to receive real-time information about the situation, the energy markets began to ease. This is one scenario where Big Data can be used to amplify information to various stakeholders to prevent panic and to ensure market stability and security of supply. Considering the novelty of this topic, our methodology is based on the meta-analysis of existing studies in the area of impacts of energy security on private companies, the national economy, and society. The results show that, in a fast-paced digital world characterized by technological advances, the use of Big Data technology provides a unique niche point to close this gap in information disparity by levering the use of unconventional data sources to integrate technologies, stakeholders, and markets to promote energy security and market stability. The potential of Big Data technology is yet to be fully utilized. Big Data can handle large data sets characterized by volume, variety, velocity, value, and complexity. Our conclusion is that the challenge for energy markets is to leverage this technology to mine available socioeconomic, political, geographic, and environmental data responsibly and to provide indicators that predict future global supply and demand. This information is crucial for energy security and ensuring global economic prosperity.
\end{abstract}

Keywords: energy security; big data; smart metering; security of supply

\section{Introduction}

Energy security and Big Data are increasingly intertwined. One the one hand, this interlacement brings forth a huge potential for the provision of energy, increasing efficiency in monitoring, and improved evaluation of current standards. On the other hand, the dependency of energy security on digitalization bears an increased risk exposure concerning cyberattacks, privacy issues, and dependence on data availability. Nevertheless, the problem of data availability is a vanishing issue since an increasing number of devices measuring energy security-relevant input variables ensure a more and more dense data 
set, which in turn increases energy security. The collection, analysis, and utilization of this collected data set is what we understand nowadays as Big Data.

The 21st century is the century of data. Big Data can be described by the so-called Five V's: Volume, Velocity, Variety, Veracity, and Value. Big Data is characterized by the collection and utilization of huge amounts of data. The process of analyzing and finding patterns in unstructured data is called data mining. Since the vast amount of data is a sufficient condition to call a data set "Big Data", the first "V" (volume) is a necessary condition to characterize a certain data collection as "Big Data". The data mining process is associated with the processual ability of the system to actually manage to analyze the data in a reasonable time. Therefore, "Velocity" is a key ingredient for Big Data to be analyzed and be made useful. The important key characteristic of Big Data is in this sense the interplay and ability of modern technology to mine these huge number of datasets in a reasonable calculation time. Due to the huge size of the data sets, they usually exhibit a" Variety" to some certain degree. The astonishing ability of data mining techniques to identify these varieties in these high volumes and at the high velocities is another feature of Big Data. Since numbers do not lie, "Veracity" is a doubtless characteristic of Big Data, which makes it so powerful and useful. Certain patterns, trends, and forecasts can be solidified and verified if they are substantiated by a huge data set. All these factors characterizing Big Data sum up to an incredible value generated by the collection and analysis of huge datasets.

While energy dependency of society has never been greater, the utilization of Big Data is increasingly important to secure energy infrastructure and energy market stability.

Considering the high importance of energy security, it is astonishing that a precise definition of energy security still does not exist. The IEA [1] defines energy security as the "uninterrupted availability of energy sources at an affordable price". For the IEA, the insurance of energy supply and maintaining the IEA emergency response capability are two key essentials to provide energy security. These capabilities include the maintenance of a "set of regulations and/or policies that provide a framework for emergency oil stockholding and data reporting, and that facilitate timely participation in IEA collective actions in case of a severe oil supply disruption".

Nevertheless, definitions such as this have to be looked at carefully. The reason for that lies in the potential conflict of interest of the originator of the definition. Like in the case of the IEA, an organization which represents primarily the interests of energy consumers, a key requirement that ensures energy security according to its definition is affordability. This is of course in the interest of any consumer and should therefore be questioned if this key requirement actually really defines energy security.

On the other side, organizations such as the US Energy Association [2] pursue the mission to "promote the sustainable supply and use of energy for the greatest benefit of all", which overlaps to a certain extent with the mostly found core definitions of energy security. As a representation organization for more than 100 companies and associations in the U.S. energy sector, including the largest Fortune 500 companies, the emphasis for energy providers lies more on the sustainability of supply of energy, as it is in the energy producers' interest to maximize the price at which they deliver their energy for the longest possible duration of affordability.

Probably, the most accurate way to define energy security is to find the common denominator of all definitions provided. However, the only definitions for energy security provided in the literature are mainly providing definitions for indicators of energy security, but not concepts for the actual measurement of energy security. To give a short overview of the most common definitions in the existing literature, we first take a look at those indicators.

Kruyt et al. [3] propose to measure energy security via distinct indicators which cover four dimensions: availability, accessibility, affordability, and acceptability. Indicators are then classified to account for energy security accordingly.

Sovacool and Mukherjee [4] define five different dimensions of energy security: availability, affordability, technology development, sustainability, and regulation. They break 
down these categories in twenty components which are all related to security of supply (SOS) and production, dependency, diversification for availability; price stability, access and equity, decentralization, and low prices for affordability; innovation and research, safety and reliability, resilience, energy efficiency, and investment for technology development; land use, water, climate change, and air pollution for sustainability; governance, trade, competition, as well as knowledge used for appropriate regulation. Furthermore, they list 372 indicators for policymakers and researchers in order to help them in their analysis, measurement, tracking, as well as in making comparisons of national performance on energy security.

Ang et al. [5] explain how various energy security indices are being constructed and how the aspect of energy security is being expanded by consideration of factors such as environmental sustainability and energy efficiency. Environmental sustainability is a big issue when it comes to energy security, since the forced energy transition leads to a change in the energy mix, promoting renewable energy at the expense of security of supply (SOS) and market price stability. Chalvatzis and Hooper [6] give an overview about the challenges which various countries face while implementing policies which target at addressing two important topics, namely climate change mitigation and improving electricity supply security.

In general, the notion of energy security is a subject to variability, which is being discussed e.g., by Yergin [7], Mueller-Kraenner [8], Kruyt et al. [3], and Chester [9].

To construct such indices and to identify synergies within the network these indices require huge amount of data, ideally generated and processed in real time.

Smart meters are an important tool, which can gather huge amounts of data in order to improve energy security and market stability, especially for the electricity market. Smart meters represent a type of power grid which can coordinate a conventional power grid and the management of advanced communication networks and pervasive computing capabilities in order to improve the control, increase efficiency, strengthen the reliability, and enhance the safety of the grid [10].

As Goertz [11] highlights, there exists a huge difference between indicators and measures, as provided in the literature regarding the definition of energy security, and analytical concepts which are the foundation for the measurement of a certain variable. The core attributes of a concept constitute a theory of the ontology of the phenomenon under consideration. Concepts are about ontology. To develop a concept is more than providing a definition: it is deciding what is important about an entity. The ontological theory of the object also provides arguments about importance of certain attributes. For this reason, we want to provide an analytical concept for measuring energy security by defining the following lemma:

Lemma 1. Energy security as a concept mitigates the impact of economic loss for private companies, national economies, and on society by the provision of stable and transparent market prices, cost reduction, homogeneity of trading rules, efficient distribution, and accessibility of energy.

Gerring [12] mentions eight criteria which need to be met by a concept in order to be perceived as good: (1) familiarity, (2) resonance, (3) parsimony, (4) coherence, (5) differentiation, (6) depth, (7) theoretical utility, and (8) field utility. Our concept of energy security tries to address these eight criteria:

(1) The concept of an economic loss is familiar to private individuals, corporations as well as governments due to the commonality of economic principles.

(2) The concept of an economic loss resonates within a society, as well as with public and private sector since it serves as a direct feedback loop which triggers immediate call for action.

(3) Parsimony reflects the most basic rational behavior and requirement for public and private households to pursue sustainable finances. 
(4) Since economic practice manifests a common way to facilitate the exchange of needs in every country and society, economic integration of the values of countries or societies provide a solid level of coherence.

(5) Our proposed concept of energy security mitigating economic loss for the public and private sector, as well as society, differentiates in a significant way from common approaches to break down energy security as a simple connectivity, accessibility, and affordability issue by considering the needs and fears of energy consumers and producers.

(6) The depth reached by our concept to classify the impact of economic acting into the different branches of public and private sector helps to better understand motives and reactions of agents acting in a certain way, thus revealing the path to energy security.

(7) The strive for economic well-being can be assumed for any rational agent involved in the pursuit for energy security, especially in a theoretical setting.

(8) The field utility can be actually measured once energy security is pursued and conducted as it manifests in the economic well-being of countries and societies.

Economic loss occurs in the aftermath of natural or forced disasters and limits societal development. Therefore, the resilience of energy systems is a very important key factor. Energy systems need to withstand shocks such as natural disasters, geopolitical conflicts, and new and emerging threats related to the ongoing digitalization of energy systems [1].

We stress in this paper the role of Big Data as a solution to energy security and investigate its potential impact on private companies, economies, and society. The focus of this paper is on security of energy supply. The methodology of this paper is based on the meta-study of existing research while summarizing possible benefits from implementation of Big Data and their impacts on private companies, national economies, and society, in general.

Our contribution to existing literature is two-fold. First, we develop a framework, which considers inclusion and analysis of impacts from the usage of Big Data on SOS as well as potentials of Big Data on the meta-levels of energy security and energy market stability. Second, we highlight the implications of Big Data on energy market stability.

While existing literature deals mainly with the identification of certain energy security indices in order to provide SOS, we provide an overview and take a comprehensive look into the role and potential of Big Data to enhance SOS and market stability. We do this by analyzing the impact of Big Data as solution to reduce uncertainty for energy security and market stability. The users of such Big Data can be companies, national governments, and the overall society. We also present in this paper evidence of how the usage of Big Data contributed to SOS.

We provide in each of the following chapters a scheme after which we analyze the role of Big Data and its impact accordingly. The scheme is the following: For each impact analysis, we first explain the role of Big Data in its relevant field. Then, we focus on the impact of Big Data on the analyzed sector, followed by highlighting new technologies for Big Data generation and utilization. We provide in the Appendix A in Table A1, a summary and comparison among our covered literature to highlight the different applications of Big Data in various areas, which are inter-connected with energy security. The cross-sectional comparison provides the key message of each source and enables us to evaluate the impacts of Big Data applications on private companies, national economies, and societies, since the goal of this paper is to highlight the importance and potential of Big Data as well as its requirements for implementation and implications on SOS and society.

Our article is structured as follows: In Section 2, we give an overview of the role of Big Data and its impact on private companies. In Section 3, we analyze the impact of the utilization of Big Data for energy security purposes on national economies. In Section 4, we analyze the impact of Big Data on society. In Section 5, we summarize the technologies described previous section and describe how they are integrated in an IoT architecture for Big Data generation and processing. Section 6 uses real world examples to discuss challenges in employing Big Data solutions for energy security assurance. 


\section{Big Data and Its Impact on Private Companies}

\subsection{Big Data for Energy Security}

Energy security is most often associated with network stability, considering the aggregate production and distribution of energy. Big Data plays an important role in the assessment of strengths and weaknesses of this network. By gathering data, forecasting as well as real-time stability evaluations are more accurately possible than forecasts and assessments based on just historical performance. Moreover, Big Data enables to identify and validate cross relationships of effects which might have remained undiscovered without the use of data mining. Understanding these relationships is crucial not only for business success, but also simply for minimizing disruptions in the network.

Disruptions of energy supply can bring significant economic damages to private companies. They can also bring damages to their reputation. This raises the question about associated costs in order to maintain at least the critical level of energy supply stability. Jun et al. [13] measure the cost of energy security in terms of supply disruption and price volatility by comparing the supply and demand of energy, which is facilitated through the use of the so-called Hirschman-Herfindahl index (HHI). The index highlights the importance of energy price stability as high price fluctuations make it more costly to match supply and demand, thus triggering higher cost of storage or even higher cost of provision. They find a number of baseload energy technologies as the most competitive energy source. The main reason for this is the prevailing balance in supply and demand of these technologies, which thus ensures a relatively stable price. Moreover, the authors find that economic security dominates supply security and is therefore the main driver for total security cost. This is, where Big Data can unfold its powerful potential to identify insights of unknown structures that explain certain pillars of economic security such as understanding effects of inflation, unemployment, and economic growth, as well as international geo-economics, a concept which is based on the cross-border economic activity amongst countries (see [14]). Other technologies are more volatile in energy generation and therefore are more prone to volatility in energy prices. The reduction of uncertainty in relation to such technologies becomes a key for decision-making processes as well as the stability of energy supply and energy prices.

Uncertainty in relation to technologies is influencing decision-making processes of all stakeholders, but for businesses, data extraction, analysis, and representation are becoming especially crucial. However, there are some challenges accompanying Big Data mining, such as risks to privacy, security, and complexity [15]. As traditional mining techniques are not able to provide cost-effective solution besides being unable to leverage parallel processing power of resources, it is inevitable to go for Big Data mining with newly built data mining technologies. Emerging technologies, such as MapReduce which is used by frameworks like Hadoop, can help in analyzing Big Data and bring about business intelligence [16].

There are also other frameworks for analyzing Big Data. For example, Hackl et al. [17] present the total site analysis (TSA) method, which is used to analyze Sweden's largest chemical cluster according to its utility system and the improvement of its energy efficiency. They show that by moderate changes to the process utility system, savings up to $60 \mathrm{MW}$ can be achieved.

\subsection{Big Data for Energy Usage Optimization}

While speaking about emerging technologies, a very efficient way to distribute energy between providers and consumers is the smart grid. It facilitates the delivery of electricity between suppliers and energy consumers through a bidirectional electricity and information flow infrastructure by meeting the pre-evaluated demand of the consumer, as well as by coordinating the electric power generation through tracking of the terminal electricity consumption, linked real-time to the power market [18]. Efficiency improvement allows for the reduction of costs for energy providers and consumers as well as to improve the reliability and stability of the energy supply. Zhou et al. [19] give a detailed overview 
of how Big Data drives smart energy management. As Big Data can be accumulated through application of sensors, wireless transmission, network communication, and cloud computing technologies, they claim that these data can be used for power generation side as well as demand side management, micro-grid and renewable energy management, asset management, and collaborative operation.

Interconnectivity, e.g., achieved through the application of smart grids, also significantly enhances market price stability. The most important factor for energy market price stability is predictive analytics and load classification which are necessary for the load forecasting, bad data correction, determination of the optimal energy resources scheduling, and setting of the power prices [20,21].

Moreover, Diamantoulakis et al. [22] stress that the scalability and flexibility can enable efficient processing of the large data volumes, usually faced in dynamic energy management and short-term power demand/supply forecasting, which in turn leads to a reduction in costs and improvement of energy security, as well as market stability. The scalability and flexibility can be ensured by the implementation of robust algorithms and provision of high-performance computing infrastructure.

An example on the types of innovative approaches to the uses of data to generate real-time supply and demand forecasts lies in shipping. Using Big Data accumulated in the maritime sector can be a viable tool not only to generate supply forecasts for specific types of maritime fuel and accordingly, prices. More interestingly, if aggregated in real time, it could provide a current demand profile for that specific sector. A sudden drop in maritime shipping activity could be a viable indicator of sudden supply shocks, as oil markets experienced during the COVID-19 crisis, potentially leading to economic and fiscal crisis among leading oil producing countries, which in turn could exacerbate negative effects on production and the world economy. It should be noted that in terms of negative effects on fiscal policy, budgetary break-even figures as opposed to production costs are most relevant (see [23]).

\section{Impact of Big Data Regulation on National Energy Security}

In accordance with Article 21 of Regulation (EU) 2015/757 of the European Parliament and of the Council on the monitoring, reporting and verification of carbon dioxide emissions from maritime transport, an EU MRV System was introduced to provide a reliable data set to set precise emission reduction targets and to assess the contribution of maritime transport towards achieving a low carbon economy [24]. As a ship specific Union MRV system, it is based on the calculation of emissions from fuel consumed on voyages to and from Union ports. The regulation applies to ships above 5000 gross tonnage in respect of $\mathrm{CO}_{2}$ emissions released during their voyages from their last port of call under the jurisdiction of a Member State and from a port of call under the jurisdiction of a Member State to their next port of call, as well as within ports of call under the jurisdiction of a Member State. The European Commission publishes a data set containing the identity of the ship, its technical efficiency, the annual $\mathrm{CO}_{2}$ emissions, the annual total fuel consumption for voyages, annual fuel consumption per distance and type of cargo, annual time spent at sea in voyages, as well as the method applied for monitoring and related data. All reports can be accessed online and are open source (see: https:/ / mrv.emsa.europa.eu/\#public/emission-report, last accessed on 12 December 2021). For 2018, the report contains more than 9.8 million entries. While certain modifications to the data would have to be made, such as daily aggregation and accessibility, the current data set can provide important insights on the real-time demand pictures and demand shocks brought about by extremely rare and unexpected events, with severe impacts on energy security and that were obvious in hindsight; so-called energy security black swans (See: [25]).

\subsection{New Technologies for Big Data Generation and Utilization}

Another viable source for Big Data to for increased energy security could come from widely applied international trade platforms that serve multi-modal transport. Trade- 
Lens [26], a platform and ecosystem to digitize global supply chains that was launched by IBM block chain and container giant MAERSK, unites a wide range of container-based trading information that could serve as an indicator for global trade movements and therefore produce an accurate real-time data-set of energy usage in the sector, if we breakdown energy consumption per container.

Other technologies for Big Data generation utilize ambient energy harvesting sources and techniques. Ambient energy harvesting sources is the process of energy scavenging or power harvesting obtained from energy prevailing in the nature. A variety of techniques are available for energy scavenging, including solar and wind powers, ocean waves, piezoelectricity, thermoelectricity, and physical motions, e.g., the conversion of random motions, including ocean waves into useful electrical energy that can be used by oceanographic monitoring wireless sensor nodes for autonomous surveillance [27].

Other new technologies such as RFID chips are able to maintain and increase value across a supply chain. New SMART RFID sensing applications allow RFID sensing and continuous monitoring such as Shelf Life Time Tracker (SLTT). SLTT is a supervision RFID system monitoring quality changes during transport of perishable foods. When addressed, the system will give a shelf-life prediction based on the used quality model. This system will be used to make appropriate management decisions that maintain and increase value across a supply chain. In addition to the shelf-life prediction, the SLTT allows for condition monitoring (temperature, humidity, etc.) [28].

Figure 1 summarizes the factors and their directional impact of big data on private companies concerning energy security.

\section{Impact of Big Data on private companies}

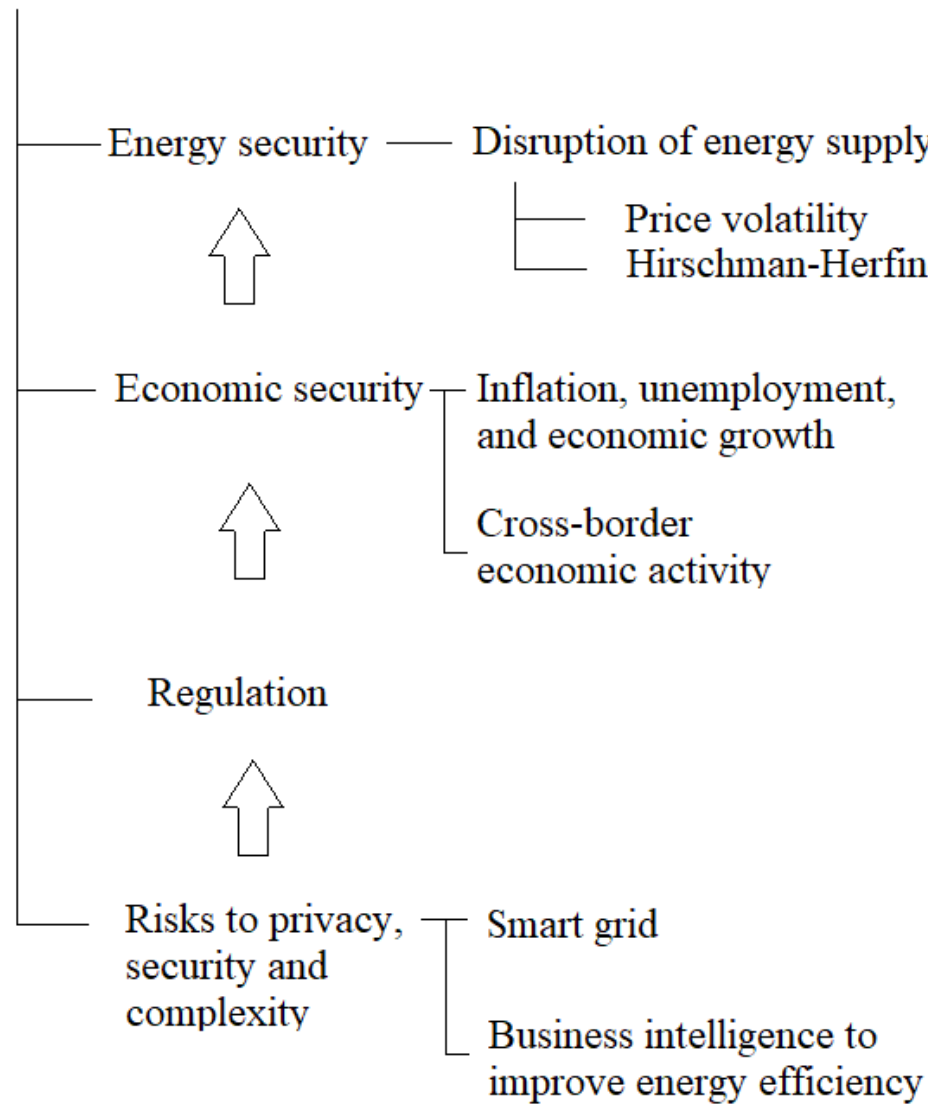

Figure 1. Flowchart diagram: Drivers of the Impact of Big Data on private companies and factors affecting energy security. 


\section{Big Data and Its Impact on National Economies}

\subsection{Big Data in Geopolitics}

How can energy security be measured in a global economic and geopolitical sense? This question is not fully answered by existing literature since there is no agreement on one methodology which considers the dynamics of international economy. One major characteristic of these dynamics is the occurrence of external shocks, e.g., caused by global financial and economic crises, political conflicts, and rebellious or war-like situations, which impact not only energy prices, but also the SOS. Radovanovic et al. [29] propose a new geo-economic concept of energy security. This concept is built upon the common indicators but extends its measurement by taking into account certain measures of economic, financial, and political stability, such as sovereign credit rating. These measures are influenced by global factors, such as the global trade of energy, or the ability of certain economies to maintain a stable environment to secure a proper energy trading framework. They construct a Geo-economic Index of Energy Security and find that GDP per capita is the most influential factor affecting the value of the Geo-economic Index of Energy Security, while the impact of sovereign credit rating is of less significant value. On the contrary, they find that energy dependence has the least impact on energy security, which is commonly used as a proxy indicator for energy security, as well as the production of energy from renewable sources, even though the latter is defined by the EU policy as one of the methods for the improvement of energy security. The reason why GDP might be identified as a more influential factor for the constructed index measuring energy security than energy dependence might be reflected in the relationship between the capability of a country to afford, promote and pay for energy security and economic development of a country. In other words, if the economic situation of a country allows for the development of more secure energy infrastructure, which in turn contributes to energy security in the sense of a more secure energy supply, then a higher level of energy security can be reached than just a certain level of energy dependency, as energy dependency only reflects the demand for energy, but not the extent to which it can be facilitated. Moreover, Bohi and Toman (1996) discuss the issues of energy security and its impact on national economies. They also investigate how the issue of energy security changed over time from the focus on military preparedness to oil quotas and oil security and further on to deregulations of energy markets and externalities and imperfections of the energy markets.

\subsection{Big Data for Identification of Energy Security-Relevant Issues}

Big Data poses a huge potential to prop up the existing methodology of analysis for energy security relevant issues since the significance of the constituents of such indexes are highly dependent on the identification of influential relationships in the data.

While speaking about energy security relevant issues, Cherp et al. [30] give a summary about these issues in the world including their significance: oil (125 countries) *, gas $(78 \text { countries })^{*}$, coal (45 countries) ${ }^{*}$, nuclear (21 countries) ${ }^{* *}$, hydro (58 countries) $* * *$, electricity (all countries), transport, industry ( $>25 \%$ of GDP in 60 countries), residential and commercial (all countries), cross-country energy supply (all countries).

It is important to understand these energy security relevant issues in relation to each country because for each of the affected countries, energy security is achieved differently. It is important to note that $10 \%$ and more of the primary energy depends on the extraction and refinement of oil. While over 5.5 billion people live in 112 countries which depend on oil for more than $18 \%$ of their total primary energy supply, energy security is mostly associated with market stability, meaning little or no market price disruptions [30]. Big Data could assist in identifying new reserves, which could be drilled at cheaper costs than locations which are being found with ordinary procedures.

For countries dependent on natural gas, energy security is being achieved through stabilization of supply as the global supply of natural gas depends upon direct investments in exploration, production, and transportation. These types of investments are usually facing a high risk-return profile since the uncertainty in drillings and production of shale 
gas fields and other production factors affect significantly the gas prices ([30], p. 342). Big Data can help identifying investment regimes under which the investment in natural gas projects is more profitable and secure.

In coal, certain countries are considered especially vulnerable. The main reasons include, on the one hand, that coal consumption in these countries has been growing more than $5 \%$ per year, and on the other hand, that these economies are very dependent on high coal intensities ([30], p. 345). Big Data could help identifying new coal reserves on the one hand, and methods to reduce coal dependency on the other hand.

In case of nuclear power, the primary concerns relate to nuclear energy infrastructure and technologies. The role of Big Data could be to identify vulnerabilities in the infrastructure and help developing new technologies to provide a safer generation of nuclear power ([30], p. 345). From a market stability point of perspective, electricity produced from nuclear energy offers a greater protection from fluctuations in raw commodity prices; while doubling uranium prices leads to a $5-10 \%$ increase in the generating cost for nuclear power, while doubling the cost of coal and gas leads to a $35-45 \%$ and $70-80 \%$ increase, respectively [31].

Hydropower is vulnerable to seasonal and annual variability in hydrological regimes, as well as local weather conditions, temperature, and precipitation in the catchment area. These factors affect not only the availability of water for hydropower production, but also the amount of pressure on water resources in a region from competing uses ([30], p. 348). Bid data could assist in forecasting weather changes and hydrological regime changes, as well as in R\&D for hydropower optimization.

By taking into account both supply and demand indicators of cross/sectoral vulnerabilities of energy systems, Big Data represents a fundamental game changer as it enables the identification of cross relationships and patterns which can be used in order to make the energy supply less vulnerable.

The change towards renewable energy poses certainly a challenge to countries. Nevertheless, via the utilization of Big Data and 5G, not only can the forecasting power of energy-related data be improved, but real time adjustments and coordination across different energy providers can also be achieved.

The importance of energy supply security is growing due to an increase in electricity dependence, expansion in the coverage of electricity grids in developing nations, an increase in the electrification of energy services, and the advancement of new energy systems, which rely on renewable energy sources.

\section{Big Data to Enhance Economic Growth}

As mentioned in the previous section, economic security is fundamental to achieve energy security. Le and Nguyen [32] find that the opposite holds too in a sense that energy security enhances economic growth, while energy insecurity measured by energy intensity and carbon intensity variables has a negative impact on economic growth. Thus, economic security and energy security are self-reinforcing agendas which need to be pursued in order to improve sustainable economic development.

As the IMF [33] already noted, the improvements in economic security contribute to the rise of private investment and decrease downside uncertainty on the return on investment. Security factors that decrease the uncertainty on the returns on investment across capital goods also directly bear on growth by enhancing efficiency of resource allocation, independent of their effect on private investment.

The IMF identifies several contributions of Big Data mining to these improvements, e.g., by gathering and assessing key variables which influence decisions on private investment, Big Data helps to define decision making rules. In terms of government leadership, Big Data has a huge potential to present inter-relationships of certain dependencies. Moreover, Big Data has the power to evaluate the external conflict risk and to identify corruption. Therefore, Big Data can be used to set up rules of law. Other influencing factors on private 
investment decisions are, e.g., racial and ethnic tensions in certain countries. Big Data can help identifying causes for these tensions and therefore help alleviating these risk factors.

A very important field of application for Big Data is the field of political terrorism and civil war threats. As Big Data comprises an almost unlimited amount of data, political relationships and the emergence and formation of counter-government can be quickly identified and the corresponding risk for escalation measured.

Furthermore, other areas of expertise can be enhanced and exploited through the application of Big Data as well, e.g., the evaluation of quality of the bureaucracy or the risk of repudiation of contracts in contractual law. A very important tool Big Data provides is the assessment of the risk of expropriation by government, which can be estimated using Big Data mining techniques. In general, Big Data can measure the degree of freedom, the possibility to exert political rights, and to measure the status of civil liberties within a country.

\subsection{New Technologies Generating and Using Big Data in Geopolitics}

One of the biggest fields relevant to the analysis, understanding and improvement of international relations is the utilization of AI applications for text mining purposes. A better understanding of international relations promotes economic prosperity, helps in mitigating geopolitical risks, and thus to promote energy security. Various fields in diplomacy, such as cyber diplomacy, utilize text mining for automated text reading, interpretation, and processing. Cyber diplomacy refers to efforts made by state representatives to shape, at the global level, the governance of cyberspace in order to prevent or penalize cyberattacks.

Big Data also promotes the diplomatic consensus on energy transition and manage its geopolitical impacts, i.e., for the prediction of the ultimate extent of a low-carbon energy system transition and the pace at which it will occur.

The importance of trust and speed in cyber diplomacy cannot be stressed enough, and thus, the importance of emerging technologies such as block chain and the improvement of transmission speed via 5G to enhance the communication network. According to McDowell and Goldstein [34], China has been active in an International Telecommunication Union (ITU) leadership group on digital object architecture, an information management system that may play a large role in the Internet of Things.

Moreover, IoT will find its applications to the political fundamental basis of energy security, which is energy diplomacy. Novel interconnections will emerge as a result, challenging traditional relations and modes of governance. Carr and Lesniewska [35] argue that advances in global climate governance appear to be offering an early model of a consensual rules-based approach within the existing international order that provides space for advancing agility, flexibility, and polycentrism to meet the demands of 'wicked problems' like the cybersecurity of the IoT.

Figure 2 summarizes the factors and their directional impact of big data on national economies concerning energy security. 


\section{Impact of Big Data on national economies}

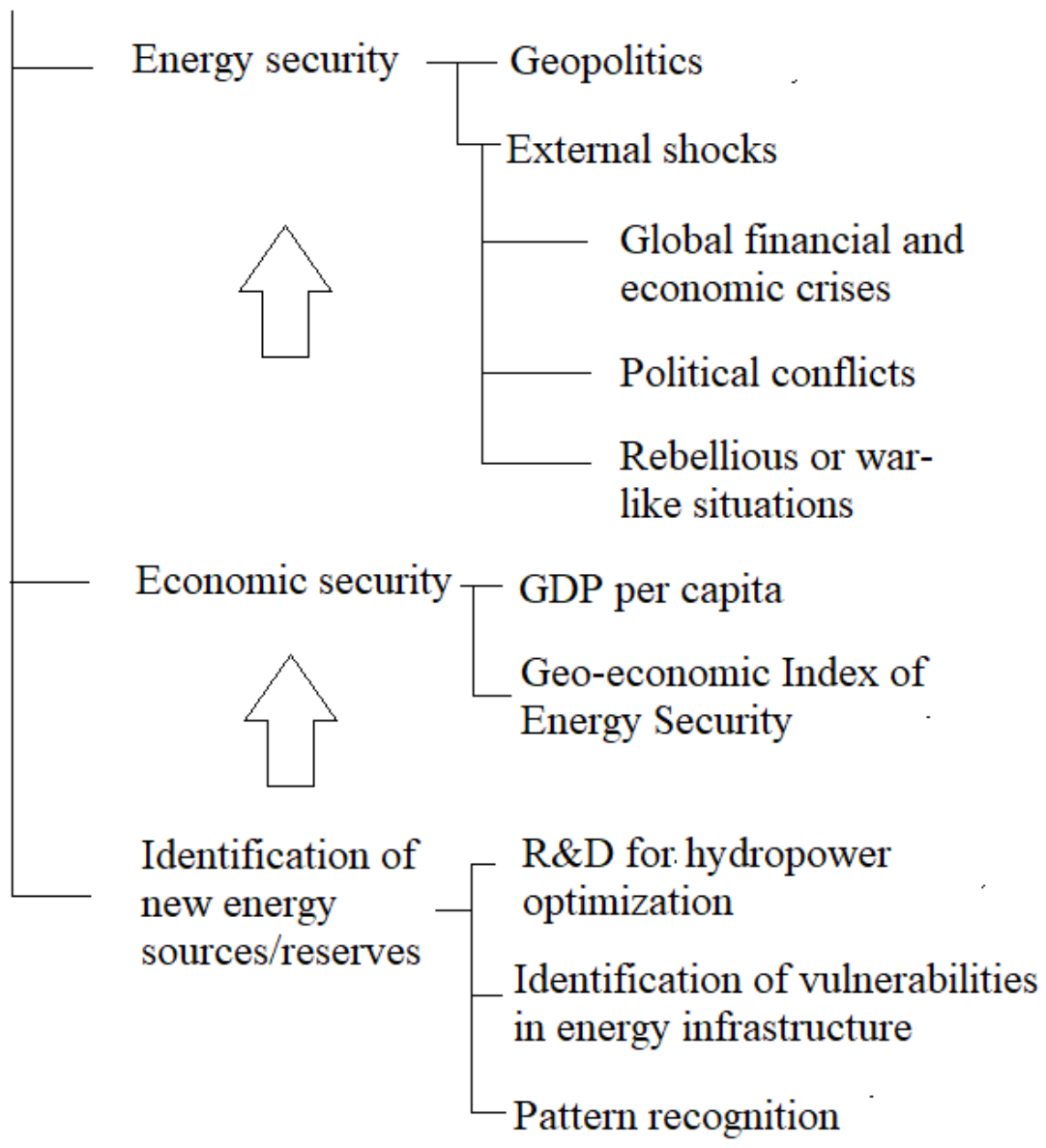

Figure 2. Flowchart diagram: Drivers of the Impact of Big Data on national economies and factors affecting energy security.

\section{Impact on Society}

\subsection{Big Data, Energy Security and Cultural Changes}

As in the previous chapters, economic security plays also an important role on society level when it comes to Big Data induced energy market stability, as one needs also to consider the relationship between the shifts from informal to formal arrangements for economic security, on the one hand, and change in the structural features of the family on the other. Houseknecht and Abdel Aal [36] lay out the premise that this shift is associated with variations in the cultural and social structural features of the family. Big Data can be useful to assess e.g., the level of family economic interdependence of workers in industrial or agricultural employment by gathering and analyzing demographic and work statusrelated statistical data.

Moreover, economic, and thus energy security can be enhanced by assessing the coverage of formal economic security programs and its relation to family economic interdependence.

One technical way to improve energy security is being pursued through the creation of a smart grid via smart meters. Smart grid remodels the existing electric power network and infrastructure by connecting communication and information technologies. This communication works based on a wireless sensor network. The smart grid enables both utility providers and customers to transfer, monitor, predict, and manage energy usage effectively and costly [37].

According to a study conducted by Electric Power Research Institute (EPRI), smart metering exhibits several advantages. On the one hand, it supports the behavioral change of a single consumer. On the other hand, the scope of the advantage goes beyond the single 
consumer and encompasses the society as a whole through the increase in social benefits. While the application of the technology itself does not produce the social benefits, it unfolds its potential when combined with other measures such as the implementation of demand response programs, the revision of outage restoration practices, and the adoption of devices that communicate consumption and price/event information to consumers [38].

The degree to which smart meters are able to enhance energy security depends a lot on the acceptance of society since with an increasing degree of coverage, the connectivity, and thus the reliability and resilience of the energy network increase. The increasing decentralization of energy prosumers (producers and consumers) comprising peer-to-peer energy networks improves live monitoring possibilities and capabilities which in turn translates into faster response and countermeasures in case of network outages. The introduction of peer-to-peer networks definitely contributes to the resilience of the energy network and thus improves energy security.

Nevertheless, the increased usage of smart meters raises some problems for society as well, as mentioned by Marres [39], who highlights that while digital technologies have enforced the spread of what he calls, a "topological imagination", they have at the same time created a sort of weak form of this "topological imagination". Marres understands topological imagination as an imaginary map which charts deterministic ideas about a certain technology as the principal driver of social change.

A major factor that Big Data plays in the context of energy security and its impact on society is the provision of low-cost energy to parts of society which would otherwise been excluded from access of affordable energy. By the identification of essential variables which lead to reduced access to energy, less available affordable energy, increased availability, and price stability, measures can be taken in order to combat the difficulty of provision of these key factors to the affected population.

Moreover, the challenge of climate change can get better understood and addressed by utilization of Big Data. The impact for society can be long-lasting one, since better forecasting and modeling techniques of weather phenomena on certain populations can help in reducing, respectively mitigating the risks of unprotected and unexpected impacts of immediate as well as prolonged changing weather conditions.

\subsection{Big Data and Privacy Issues}

There are also privacy issues involved in the creation and usage of Big Data. Zhang [40] mentions the following risks for society, which need to be addressed and considered when using Big Data to enhance energy security: privacy risks, Big Data credibility, as it needs to be confirmed, Big Data privacy protection technology is lacking, and threats to data security. In order to come by these risks, he proposes to improve the privacy protection legal mechanism, the establishment of a privacy protection agency, and the improvement of people's awareness and quality of data.

Liu [37] mentions that the increased application of wireless sensor network raises new security challenges related to privacy issues, connectivity problems, and security management, causing unpredicted expenditures and potentially causing damage to utility providers as well as consumers.

\subsection{New Technologies Affecting Society}

Fog computing will have a tremendous impact on daily usage of devices for society since the emergence of the Internet of Things (IoTs) requires mobility support and geodistribution in addition to location awareness and low latency.

Fog computing is a highly virtualized platform that provides compute, storage, and networking services between end devices and traditional cloud computing data centers, typically, but not exclusively located at the edge of network. Fog computing extends the cloud computing paradigm to the edge of the network, thus enabling a new breed of applications and services. The "pay-as-you-go" cloud computing model is an efficient alternative to owning and managing private data centers (DCs) for customers facing web 
applications and batch processing, which makes the fog the appropriate platform for a number of critical Internet of Things (IoT) services and applications, namely connected vehicle, smart grid, smart cities, and, in general, wireless sensors and actuators networks (WSANs) [41].

Another huge impact of new technologies utilizing big Data comprises the emergence of IoT and its form of communication. The main communication form of the present Internet is human-human. The Internet of Things can be considered as the future evaluation of the Internet that realizes machine-to-machine (M2M) learning. Thus, IoT provides connectivity for everyone and everything. The IoT embeds some intelligence in Internet-connected objects to communicate, exchange information, take decisions, invoke actions, and provide amazing services [42].

Therefore, the way people interact and communicate will be tremendously affected by the emergence of IoT since communication will take place not only human-to-human anymore, but human-to-machine.

Another new technology emerging in the proliferating field of IoT is Edge computing. Edge computing is a development of cloud computing. It has the potential to address the concerns of response time requirement, battery life constraint, bandwidth cost saving, as well as data safety and privacy. This technology is likely to improve work speed, response times, data safety and privacy, and thus make the pace of life faster. It can be applied to cloud offloading, smart homes and cities, as well as collaborative edge [43].

Figure 3 summarizes the factors and their directional impact of big data on society concerning energy security.

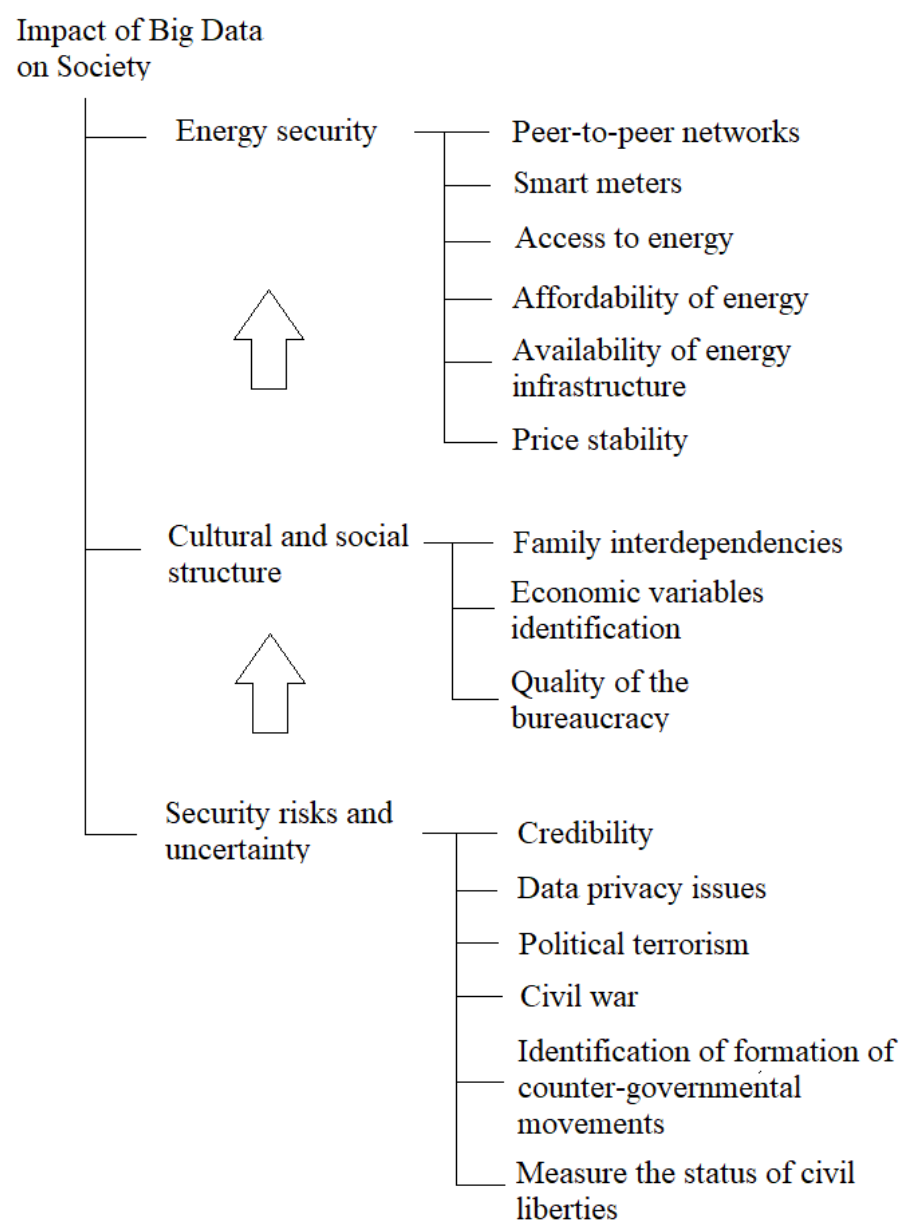

Figure 3. Flowchart diagram: Drivers of the Impact of Big Data on national economies and factors affecting society. 
We provide in the Appendix A, in Table A1, a cross-sectional comparison among the Big Data applications, which are energy-security relevant for our article. The purpose is to present an overview how certain technologies are used and in which contexts they are deployed.

\section{IoT Applications}

In this chapter we provide an overview of IoT-related issues concerning the impacts on private companies, economies, and society. First, we provide an IoT architecture for the devices mentioned in the previous chapter, which describes the appropriate framework in which Big Data can be generated, processed, and utilized in order to enhance energy security. Secondly, we turn to IoT-related security issues, which appear in the process of Big Data generation and utilization. In most cases, these issues arise out of privacy, security, and energy inefficiencies, but can also comprise communication incapacities of IoT devices and servers. Thirdly, we present other applications

\subsection{IoT Architecture for Big Data Generation and Processing}

In order to unfold its power, IoT needs devices, which can process and operate pre-programmed, or learned tasks. Therefore, it is important to define an appropriate architecture which serves as a platform to perform the needed code sequences on the corresponding devices. As an example, we focus in Figure 4 on a simple as well as sophisticated consumer IoT device, as done in ETSI [44]. The framework holds for commercial application in private companies, national energy providers, and cross-national energy grids. A consumer IoT device is a collection of hardware and software components, generally with physical interfaces which can also be network interfaces.

\section{Example Simple Device}

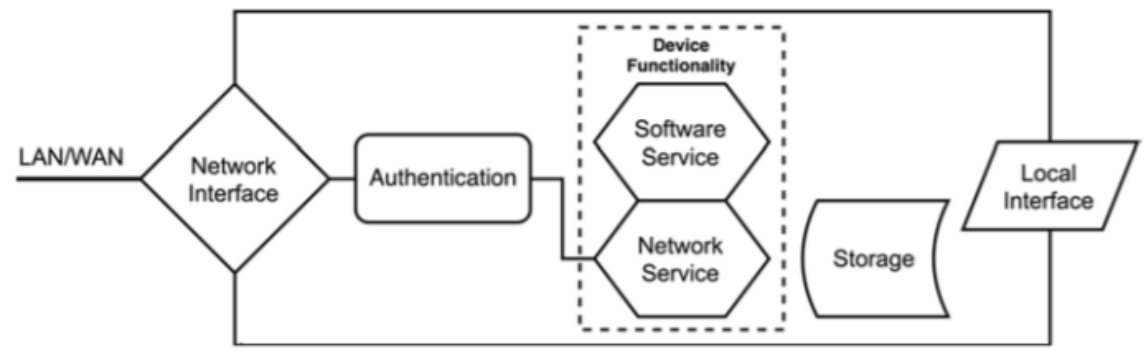

Example Sophisticated Device

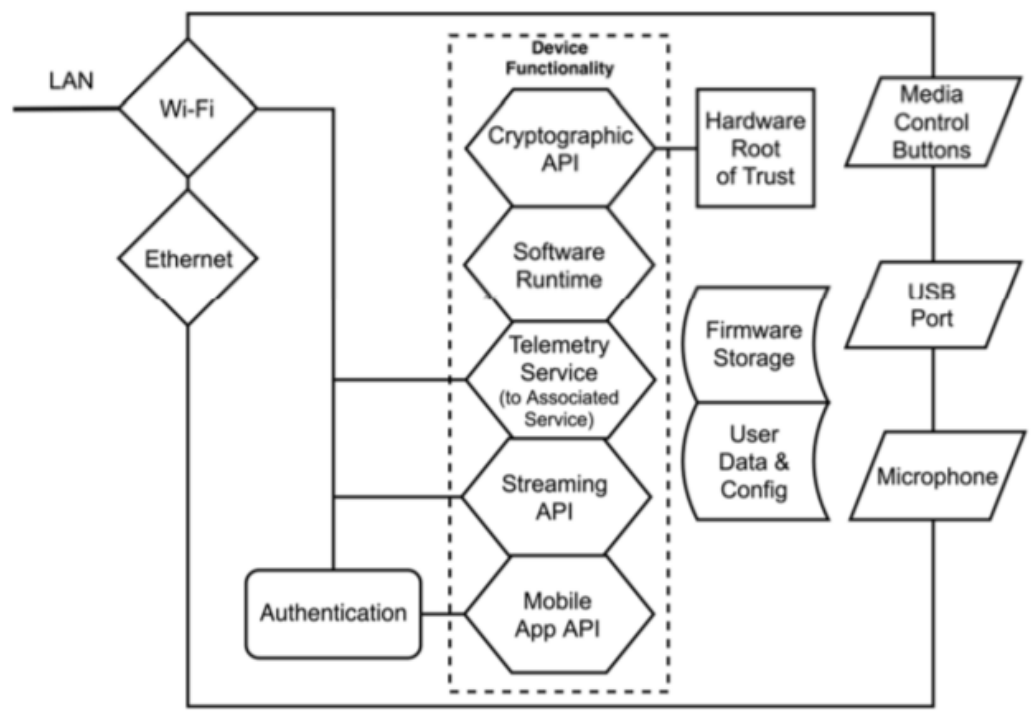

Figure 4. Examples of a general architecture of a device and of an architecture for an IoT device [44]. 


\subsection{IoT for Energy Security}

Sen et al. [45] investigate the security, energy-efficiency, and communication capacity of IoT devices and compare wireless IoT devices. Their main insight is that an important unmet need for security solutions is context awareness. One would want not to have to spend precious energy resources on a security protocol (which can often involve expensive network communication) if the environment is benign.

Tawalbeh, et al. [46] explore privacy and security issues related to IoT, such as caused by improper device updates, lack of efficient and robust security protocols, user unawareness, and famous active device monitoring. They explore the background of IoT systems and security measures and identifying (a) different security and privacy issues, (b) approaches used to secure the components of IoT-based environments and systems, (c) existing security solutions, and (d) the best privacy models necessary and suitable for different layers of IoT driven applications. They also implemented security certificates to allow data transfer between the layers of the proposed cloud/edge enabled IoT model.

Thirdly, we can summarize the limitations and benefits of IoT utilization to generate Big Data. Hossein et al. [47] identify the integration of renewable energy and optimization of energy use are key enablers of sustainable energy transitions and mitigating climate change. They highlight the role of energy supply, transmission and distribution, and demand. IoT can be employed for improving energy efficiency, increasing the share of renewable energy, and reducing environmental impacts of the energy use. They also discuss the enabling technologies of IoT, including cloud computing and different platforms for data analysis, and review challenges of deploying IoT in the energy sector, including privacy and security, with some solutions to these challenges such as blockchain technology.

Bekara [48] analyzes security issues and challenges for an IoT-based Smart Grid, since IoT often makes reference to the integration of (resource-constrained) objects, such as sensors, actuators, RFID tags, or any device involving a communicating interface and a computing capability, into the Internet. These are subject to sever security challenges, such as scalability, mobility, deployment, legacy systems, constrained resource, heterogeneity, interoperability, bootstrapping, trust management, and latency/time constraint. Security services for the IoT-based smart grid can inclyde authentication, data integrity, confidentiality, user's privacy, and authorization and control access. The detailed definitions of these security issues and services can be found in [48].

Trappe et al. [49] also highlight the limits and opportunities in the IoT. They stress that many new "networkable" devices, which constitute the Internet of Things, are low energy and lightweight. These devices must devote most of their available energy and computation to executing core application functionality, making the task of affordably supporting security and privacy quite challenging. They present the viewpoint that current cryptographic tools cannot easily secure the "low end" of the IoT, as the operating energy and computational regime are not conducive to traditional security approaches. They conclude that, ultimately, the IoT's future will rely on our ability to adequately secure hard-to-secure, resource-sparse devices.

Electric cars will play a very important role in the future of any electricity grid and the required network of charging stations ought to not only save energy, but deploy it within the network to the station where it's needed. IoT devices are prone of facilitating such a service. Typical devices are on-board sensors in cars or sensors in charging stations. In order to facilitate a certain degree of energy security in a setup of a charging stations network, an optimal power utilizing strategy for PV-based EV charging stations is important [50]. Moreover, the simultaneous planning of PEV charging stations and distributed generations is crucial, considering financial, technical, and environmental effects [51,52].

However, the devices used for measurement are subject to certain constraints, such as limitations in computational speed and power, data storage, exposure to externalities, incompatibilities, error messaging, etc. 


\subsection{IoT for Energy Issues}

Typical energy issues encompass dysfunctions in the facilitation of a stable energy grid, which lead to price insecurity and oscillation of voltage, and may potentially lead to a blackout. Other issues arise out of the threat of cyberattacks. IoT provides some interesting tools that utilize and leverage Big Data to better measure and predict, for instance, energy demand.

One of the most important applications of IoT is the Smart Grid (SG). SG is a data communications network, which is integrated with the power grid to collect and analyze data that are acquired from transmission lines, distribution substations, and consumers [53]. According to the National institute of standards and technology [54], the smart grid has certain required functionalities to deploy the smart grid. Ghasempour [53] summarizes these functionalities in the following way:

1. Communication networks: Public, private, wired, and wireless communication networks that can be used as the communication infrastructure for smart grid [55].

2. Cybersecurity: Determining measures to guarantee availability, integrity, and confidentiality of the communication and control systems which are required to manage, operate, and protect smart grid infrastructures [56].

3. Distributed energy resources: Using different kinds of generation (e.g., renewable energies) and/or storage systems (batteries, plug-in electric cars with bi-directional chargers) that are connected to distributed systems [57].

4. Distribution grid management: Trying to maximize the performance of components in distribution systems such as feeders and transformers and integrate them with transmission systems, increase reliability, increase the distribution system efficiency, and improve the management of distributed renewable energy sources [58].

5. Electric transportation: Integrating plug-in electric vehicles in a large-scale [59].

6. Energy efficiency: Providing mechanisms for different kinds of customers to modify their energy usage during peak hours and optimizing the balance between power supply and demand [60].

7. Energy storage: Using direct or indirect energy storage technologies such as pumped hydroelectric storage technology [61].

8. Wide-area monitoring: Monitoring of power system components over a large geographic area to optimize their performance and preventing problems before they happen [62].

9. Advanced metering infrastructure (AMI): AMI as one of the key components of SG creates a bidirectional communication network between smart meters (SMs) and utility system to collect, send, and analyze consumer energy consumption data [63-65].

These technological advances show the power and ability of IoT to cope with energy issues arising out of normal operation. However, there are also challenges arising from the increasing dependency on IoT which encompass reliability or compatibility issues. Reliability issues might occur simply due to the fact that the devices and sensors have to operate under high or low temperatures, high voltages, exposure to electromagnetic waves, exposure to water, etc., while compatibility problems might arise out of the fact that IoT devices and different sensors operate on batteries. Therefore, the development and integration of smart energy harvesting setups are crucial.

Another issue of IoT deployment comes with its high energy usage and amount of collected data, which makes it susceptible to cyberattacks. The bottleneck is the Internet per se. Since data harvesting, transmission, communication, and processing works through nodes over the Internet, these nodes are exposed to hacking attacks as well as blackouts. Therefore, back-ups and independent interoperability between these nodes are of the highest importance to ensure a safe network. Key to reaching a higher degree of such safety would be standardization. 


\subsection{IoT in Temperature Sensing}

IoT finds many applications to generate Big Data which are energy security-relevant. One of the most important applications is temperature sensing. We will explain first why and how temperature sensing is a crucial IoT application, before presenting a real-life practical use case of IoT for temperature sensing to improve energy security.

There exist different types of sensors designed for performing different types of tasks, such as measuring temperature. They range from measuring environmental temperature data, meteorological temperature data, healthcare and bio-medical temperature data [66], smart-building data [67], agricultural temperature data [68], to fashion and sports temperature data [69].

The measurement of temperature is usually performed through devices. Ninja Blocks can be identified as the latest development in which IoT and cloud computing converge. Ninja Blocks are small and cheap devices which encompass a variety of different sensors such as acceleration, temperature, current, humidity, motion, distance, sound, light, and even capture video. They have the capability to identify some of an event that occurred based on the sensor data and perform actions, such as tweet, sms, email, Facebook or Dropbox uploading. Another similar type of device used for the generation of Big Data is the i-voltmeter [70].

Fiber sensors are the most commonly used type of sensors for temperature sensing and are used in aerospace, defense, security, civil engineering, and the oil and gas industry, e.g., for measuring temperature changes in a pipeline monitoring system [71,72]. Temperature sensors are usually used in harsh production environment where high temperatures prevail and endanger the manufacturing process [73].

Another typical field of application of temperature sensors is M2M data, namely data obtained from readings made by machine sensors that measure pre-set conditions at regular intervals. Examples of the data that are collected include log data, geo location data, CPU utilization, temperature, rules, etc. [74] Temperature sensors are very important even when to the maintenance of the IoT enabling infrastructure itself, e.g., for temperature measuring of IoT gateways, $\mathrm{WiFi}$, cables, etc. [75]. Temperature sensors are also used for farming and includes data collection from crop monitoring, mapping, drones, aircrafts, wireless sensors, smart phones, etc. Another field of application of temperature sensors is iron and steelmaking i.e., a parallel gray-box model that was developed for entry temperature estimation of secondary scale breaker [76].

A very interesting application of Big Data through IoT is the incorporation of big data and social sensors in an early warning system of dengue outbreaks through data collection of rainfalls, temperature, and humidity, which can dramatically affect the population of mosquito vectors [77].

Temperature sensors are also used for multi-source energy harvester that collect electromagnetic energy and thermal energy (both available $24 \mathrm{~h}$ ) from the ambient environment simultaneously. The motivation behind this application is that billions of wireless sensing devices must be powered for IoT applications. Despite the fact that solar energy has been one of the main sources of ambient energy due to its availability, higher power density, and the maturity of the solar photovoltaic industry, there are many scenarios (indoor environment, outdoor environment during nighttime, poor weather conditions, underground, etc.) where ambient solar energy is either not available or not sufficient for practical applications. Therefore, for such scenarios, other renewable sources of energy, such as multi-source energy harvester, must be sought. The idea is that this IoT application uses temperature and humidity sensors which are powered by the multi-source energy harvester [78].

We next provide a use case, which stresses the practical issues and challenges associated with the application of Big Data to improve energy security. 


\section{Use Case: Practical Issues and Challenges}

\subsection{Risks to Energy Supply}

As mentioned above, each energy consumer firm has two major risks related to its energy supply: "changes in energy price" and "energy supply disruption". Changes in energy price increases firm's total cost and affects firm's break-even-point and profit margin. Energy supply disruption could affect firm's productivity and damage their brand. In order to manage the energy risks, firms need to quantify these risks. Quantifying risk indicators makes it possible to forecast the energy related risks and identify the risk drivers (factors). For instance, it is logical to assume that the maximum and minimum temperature affects electricity and natural gas price. Thus, it is necessary to forecast the annual temperature to forecast average energy price (to calculate breakeven point, etc.) as well as the worst-case scenario under given risk level. The worst-case scenario in risk level $\alpha \%$ is a point which there is only $\alpha \%$ chance that the energy price will exceed this point. Using worst case scenario forecasts, firms can build a portfolio to hedge the energy price risk. As it can be seen, in order to successfully hedge their energy price risk, firms need to accurately forecast the risk factors like annual temperature.

\subsection{Use Case of Big Data Applications for Energy Security}

To better understand the role of big data analytics for private firms' energy security, let's consider a private firm as medium size electricity or natural gas consumer in Europe. For this example, we are considering three largest economies in the Europe, i.e., Germany, UK and France. These economies have different energy structures. In Germany, most of the energy supplies come from oil, natural gas, and coal. The UK mostly rely on natural gas and oil, while in France nuclear power and oil are the main sources for energy supply. Figures 1 and 2 show the energy source's share in total energy supply and their share in generated electricity, in 2019 for these countries (the data are downloaded from IEA's data browser [79]). In addition to differences between energy supplies in these economies, their energy consumption patterns and energy firms are different as well. For instance, the most energy consumption in the domestic section of Germany and UK is

used for heating while in France (mostly in south) it used for both heating and cooling, due to their weather conditions. This means that lower temperature in Germany and UK increase energy demand in domestic section and possibly leads to increase in energy price (i.e., natural gas and electricity price). In France, on the other hand, both an increase and decrease in temperature will lead to higher energy demand and increase the chance of higher energy price. However, since nuclear power is the main source in electricity generation in France, and given the fact that households mostly use electricity for air conditioning and natural gas (or heating oil) for heating, we should expect an increase in electricity demand when temperature rises and an increase in natural gas price when temperature decreases. Furthermore, in the UK and France stock markets, there exists large oil and gas upstream companies and dedicated stock market indexes (FORG index in France and FTUB0500 in UK), while in Germany, most energy firms present in the oil and gas section are active in midstream fields (distribution, processing, etc.). Figure 5 reports the largest per capita electricity consumptions by source in 2020, while Figure 6 provides an overview of the per capita electricity from fossil fuels, nuclear and renewables in 2020. We can see that the majority of all electricity consumption and generation is still fossil-based. According to the IEA Energy policy report for Germany 2020, fossil fuels account for around $80 \%$ of total primary energy supply (TPES) in Germany, close to the median among IEA member countries. 
Coal $\square$ Gas $\square$ Oil $\square$ Nuclear $\square$ Hydropower $\square$ Wind Solar $\square$ Other renewables

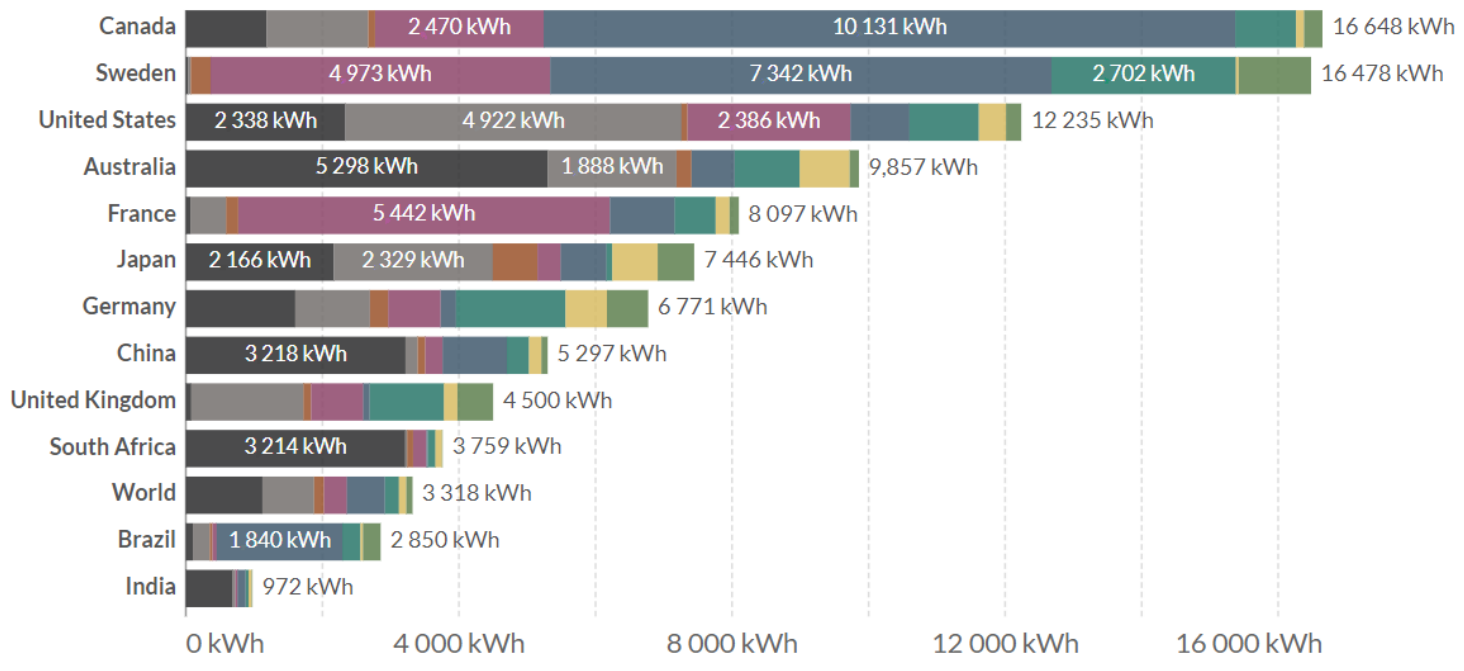

Source: Our World in Data based on BP Statistical Review of World Energy \& Ember $\quad$ OurWorldlnData.org/electricity-mix $\bullet$ CC BY

Figure 5. Per capita electricity consumption by source, 2020 (Source: https: / / ourworldindata.org/ electricity-mix, last accessed on 12 December 2021).

Fossil fuels

Nuclear $\square$ Renewables

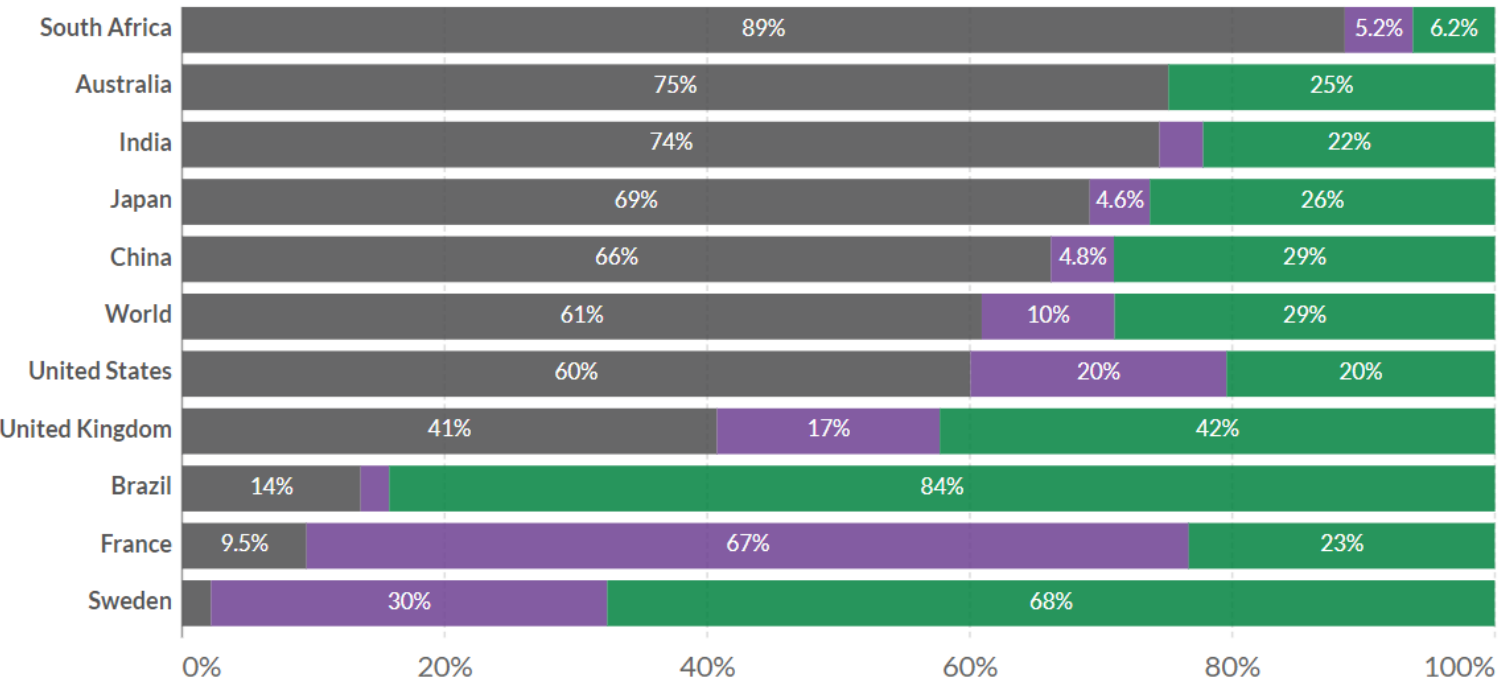

Figure 6. Per capita electricity from fossil fuels, nuclear and renewables, 2020 (Source: https:/ / ourworldindata.org/electricity-mix, last accessed on 12 December 2021).

Using the above discussion, a private firm, such as a medium size electricity or natural gas consumer, may consider the annual temperature as a risk factor for its energy security and use the financial instruments in the oil and gas section of stock market to hedge their energy risk. Table 1 shows the Spearman correlation between temperature, energy price and some financial instruments in Germany, UK, and France, for annual data from 2008 to 2019 (Temperature data were downloaded from Climate Research Unit, University of East Anglia, database [80]. The energy price data were downloaded from Eurostat database [81]. The Electrawinds SE A stock price (EWI1) from Germany, FTSE ALL Oil \& Gas index (FTUB0500) from UK, and French CAC Oil and Gas (FROG) index data were accessed from investing.com [82]. Since the Frankfurt stock market does not provide an oil and gas index, we used the stock price of an energy firm with the highest correlation to the energy price in Germany). 
Table 1. Spearman correlation between annual temperature, energy price and some financial instruments in Germany, UK and France.

\begin{tabular}{|c|c|c|c|c|c|c|}
\hline Country & & $\begin{array}{c}\text { Annual } \\
\text { Average } \\
\text { Temperature }\end{array}$ & $\begin{array}{c}\text { Annual } \\
\text { Minimum } \\
\text { Temperature }\end{array}$ & $\begin{array}{c}\text { Annual } \\
\text { Maximum } \\
\text { Temperature }\end{array}$ & $\begin{array}{l}\text { Natural } \\
\text { Gas Price }\end{array}$ & $\begin{array}{c}\text { Electricity } \\
\text { Price }\end{array}$ \\
\hline \multirow{3}{*}{ Germany } & $\begin{array}{l}\text { Natural } \\
\text { Gas Price }\end{array}$ & -0.2772 & -0.2676 & -0.3719 & - & 0.6643 \\
\hline & $\begin{array}{l}\text { Electricity } \\
\text { Price }\end{array}$ & -0.5929 & -0.5916 & -0.6421 & 0.6643 & - \\
\hline & EWI1 & -0.3782 & -0.4770 & -0.4854 & 0.8167 & 0.95 \\
\hline \multirow{3}{*}{ UK } & $\begin{array}{l}\text { Natural } \\
\text { Gas Price }\end{array}$ & -0.0456 & -0.0599 & 0.1757 & - & 0.8322 \\
\hline & $\begin{array}{l}\text { Electricity } \\
\text { Price }\end{array}$ & -0.1333 & -0.1094 & -0.0598 & 0.8322 & - \\
\hline & FTUB0500 & 0.3669 & 0.3015 & 0.3684 & 0.0839 & -0.2587 \\
\hline \multirow{3}{*}{ France } & $\begin{array}{l}\text { Natural } \\
\text { Gas Price }\end{array}$ & -0.3636 & -0.3233 & -0.3923 & - & 0.1468 \\
\hline & $\begin{array}{l}\text { Electricity } \\
\text { Price }\end{array}$ & 0.5384 & 0.5975 & 0.4658 & 0.1468 & - \\
\hline & FROG & 0.4182 & 0.4834 & 0.3109 & -0.2308 & 0.3287 \\
\hline
\end{tabular}

As it can be seen in Table 1, the annual temperature is a risk factor for energy price in France and Germany, since there is correlation between annual temperature and natural gas and electricity prices. In the UK, however, annual temperature is not a risk factor for energy price, since there is not a strong correlation between annual temperature and natural gas and electricity price. As expected (and discussed before), in France, the increase in annual temperature increases the electricity price and a decrease in annual temperature leads to an increased natural gas price. On the other hand, an increase in temperature leads to a higher return in France oil and gas stocks. Based on this simple analysis, a firm in France may use FROG stocks to hedge their electricity price risk, but not "natural gas price" risk (negative correlation between "annual natural gas price and FROG index suggests that an increase in annual natural gas price may leads to decreased FROG index). In Germany, a decrease in annual temperature results in increased electricity and natural gas prices (due to negative correlation). Since the "EWI1" price has positive correlation with both natural gas and electricity price, a firm in Germany may use "EWI1" to hedge their energy price risks. In the UK, however, the use of financial instrument correlated with annual temperature (like FTUB0500) is not a good strategy to hedge the firm's energy price risk, since the correlation between annual temperature and energy price is low and the correlation between annual temperature and FTUB0500 index is relatively high. Furthermore, the electricity and natural gas prices in UK does not have high positive correlation with market oil and gas index, FTUB0500.

\subsection{Implications for Big Data Applications}

As discussed above, a medium size electricity or natural gas consumer firm should use different hedging strategies in these countries. In Germany, the firm can use a portfolio of energy firms' stocks like "EWI1" to hedge the energy price risk for both electricity and natural gas. In France, this strategy (using a portfolio of energy firms in "FROG" index) only works for hedging electricity price risk. For hedging natural gas price risk, we should find another financial instrument. In the UK, the strategy of using a portfolio of energy firms in "FTUB0500" index does not help hedging electricity or natural gas price risks. In other words, the firm should find other financial instruments for hedging their energy price risk.

One simple solution for firm to control their electricity and natural gas price risk is to use a statistical model to forecast electricity and natural gas price and "oil and gas" stock in 
the market (e.g., "FROG" index in France and "EWI1" in Germany). Using simple linear regression with temperature as predictor, we would have following forecasting equations (we used only minimum temperature in France since it has the highest correlation with "Electricity Price" and "FORG" and maximum temperature in Germany). Table 2 shows the estimated forecasting equations with annual temperature maximum and minimum temperature as predictors.

Table 2. Estimated forecasting models for hedging energy price risks.

\begin{tabular}{|c|c|c|c|}
\hline Country & & Estimated Regression Model & $\mathbf{R}^{2}$ \\
\hline \multirow{5}{*}{ Germany } & $\begin{array}{c}\text { Natural Gas Price } \\
\text { Forecasting EFquation }\end{array}$ & $N G P_{t}=0.07-0.0026 M T_{t}+\varepsilon_{t}$ & 0.1431 \\
\hline & $\begin{array}{c}\text { Electricity Price } \\
\text { Forecasting Equation }\end{array}$ & $E P_{t}=0.1544-0.0049 M T_{t}+\varepsilon_{t}$ & 0.3695 \\
\hline & $\begin{array}{c}\text { EWI1 } \\
\text { Forecasting Equation }\end{array}$ & $E W I 1_{t}=44.33-2.931 M T_{t}+\varepsilon_{t}$ & 0.2478 \\
\hline & $\begin{array}{c}\text { Natural Gas } \\
\text { Price/EWI1 } \\
\text { Coefficient Ration }\end{array}$ & $\frac{0.0026}{2.931}$ & - \\
\hline & $\begin{array}{c}\text { Electricity Price/EWI1 } \\
\text { Coefficient Ratio }\end{array}$ & $\frac{0.0049}{2.931}$ & - \\
\hline \multirow{3}{*}{ France } & $\begin{array}{c}\text { Electricity Price } \\
\text { Forecasting Equation }\end{array}$ & $E P_{t}=0.02958+0.00523 m T_{t}+\varepsilon_{t}$ & 0.284 \\
\hline & $\begin{array}{c}\text { FROG } \\
\text { Forecasting Equation }\end{array}$ & $F_{R O G}=354.93+65.31 m T_{t}+\varepsilon_{t}$ & 0.1445 \\
\hline & $\begin{array}{l}\text { Electricity Price/FROG } \\
\text { Coefficient Ratio }\end{array}$ & $\frac{0.00523}{65.31}$ & - \\
\hline
\end{tabular}

$M_{t}$ : annual maximum temperature; $N G P_{t}$ : annual average of natural gas price; $E P_{t}$ : annual average of electricity price; $E W I 1_{t}$ : annual minimum temperature; $F R O G_{t}$ : France CAC Oil and Gas price index.

According to these Table 2, one Celsius degree increase in annual minimum temperature increases average electricity price by 0.00523 Euros and average FROG index by 65.31 Euros, in France. In Germany, one Celsius degree decrease in annual maximum temperature increases average electricity price by 0.0049 Euros, average natural gas price by 0.0026 and average EWI1 by 2.931 Euros. In order to hedge the energy price risk, the firm can use the "Electricity Price/FROG" coefficient ratio in France and "Electricity Price/EWI1" and "Natural Gas Price/EWI1" coefficient ratio in Germany can be used to build a financial portfolio. For instance, if the firm is estimated to consume $N$ kWh electricity in next year, in France, they may invest $\frac{0.00523}{65.31} \mathrm{~N}$ Euros (build a portfolio) in CAC Oil and Gas companies. In Germany, however, the firm may invest $\frac{0.0049}{2.931} N$ Euros for $N \mathrm{kWh}$ electricity consumption or $\frac{0.0026}{2.931} N$ Euros for $N \mathrm{kWh}$ natural gas consumption, in EWI1.

This simple example shows the number of practical issues in managing the energy price risk. The first issue is finding the risk factors. As can be seen in Table 1, while annual temperature can be used as an energy price risk factor in some economies (like Germany and France), there are other risk factors in other economies (like UK). Even in Germany and France, the annual temperature only explains some of the variations in energy price (correlations or not close to 1 or -1 ). Low correlations between annual average temperature and energy prices indicates that there are risk factors other than annual temperature. Using big data mining, one can find other energy risk factors (e.g., social, economic, or environmental factors) for a given firm, although employing such solutions require access to multiple socio-economic and environmental databases.

Another issue is forecasting risk factors. As it can be seen in Table 2, risk factors (such as annual temperature) are predictors in forecasting models for energy price and related financial instruments. In order to use these models, we should first forecast the risk factors. 
Using big data analytics makes it possible to find accurate forecast for risk factors [83]. For instance, big data solutions are widely used to forecast the climatic variables [84]. GEFS (Global Ensemble Forecast System), GFS (Global Forecast System), and ECMWF (European Center for Medium range Whether Forecast) are some of the famous platforms used for providing such forecasts. However, the forecasts from these models are not necessarily the same. These forecasts usually need to be combined using existing climatic big data (observed data from weather stations, satellite data, etc.) and probabilistic methods [85]. Although big data solutions are well developed for forecasting some risk factors (like weather conditions), there are not many solutions for other forecasting other risk factors. For instance, forecasting socio-economic variables affecting energy demand is a challenge itself [86].

Estimating energy price and its worst-case scenario is another issue in managing energy risks. The relation between energy price and its risk factors is not necessarily linear. Many researches in energy demand forecasting have shown the nonlinear behavior in energy demands $[87,88]$. Using big data mining and machine learning algorithm, one can find a nonlinear dynamic model to estimate the energy price's drivers and its worst-case scenario $[89,90]$.

\subsection{Conclusions Drawn from Use Case}

Finally, finding right financial tool to hedge the energy risk, is another self. For instance, oil and gas index can be used to hedge electricity price risk in France, whilst it is not appropriate for hedging natural gas price risk (since, according to Table 1, FROG has positive correlation with electricity price, but negative correlation with natural gas price). In the UK, however, the oil and gas index is not useful for hedging either of electricity or natural gas price risk (since, according to Table 1, the FTUB0500 does not have large positive correlation with electricity or natural gas price). In Germany, on the other hand, the situation is different. Since the stoke market does not provide an oil and gas index, one should find another financial instrument. In the above example, we searched the entire energy section in Frankfurt stock market to find a suitable instrument with high positive correlation with electricity and natural gas price. As can be seen from this example, there is not a unique financial instrument or hedging strategy, and in order to build the appropriate portfolio to hedge energy risks, one should analyze the stock market and finds relations between stock prices and energy risk factor movements. In practice, one financial instrument can be used to hedge some energy risks and increase other risks at the same time. For instance, as discussed above, FROG can be used to hedge electricity price risk however it will increase the natural gas price risk, since it has negative correlation with natural gas price. There is a growing body of literature proposing big data solutions for risk management [91]. The advantage of using big data solutions in risk management, is their ability for fusing quantitative data (like financial variables, stock price, etc.), and qualitative data (like sentiment data from social networks, published policy documents etc.) $[91,92]$. In an energy risk context, however, the use of big data solutions is relatively novel. For instance, Cerchiello and Giudici [93] proposed a big data solution to use financial analysis (on financial data) and sentiment analysis (on related news feeds) for managing financial risks in Italian banks. Specific solutions to hedging energy price risks are proposed. Kou et al. [94] provides a comprehensive list of methods for and objectives for developing systematic risk analysis based on big data solution. Although there are large number of researches proposing machine learning methods (as it is suitable for big data analytics) for hedging energy price risks (see, $[95,96]$ for example), there are not many studies focusing on developing big data solutions specifically for the energy price risk. The main challenge in developing such solutions is to access the multiple data warehouses and fuse results from different sources [27].

In a larger scale, the policy makers need to manage country's energy related risks. As mentioned before, instability in energy resources has negative impact on socio-economic variables. As an immediate consequence of increased energy prices or disruption in 
energy supply, the rate of energy poverty increases in society. Accordingly, it increases social distress, healthcare costs and affects households' ability to provide work force and contribute to the economy [86]. Furthermore, an increase in energy prices affects the global economy through its effect on private firms (as discussed). Governments and policy makers use different approaches to reduce energy risks and secure energy supply, from supporting energy supply firms and reducing their operational risks (e.g., geopolitical risks, cash flow risks, etc.) to investing in new technologies for renewable energies, even supporting households and small firms against energy risks. Policy makers need to have a comprehensive understanding of energy risk factors and energy supply situations, in order to choose between policies and approaches. For instance, if the policy makers choose to invest in renewable energy sources for long term energy supply, they should first investigate the availability and sufficiency of such resources [86]. One needs to have the driver factors of energy demand, amount of accessible energy resources, and the variables related to final cost of energy supply to find the most cost efficient and sustainable energy policies. Using this information, policy makers can estimate how much energy they need to achieve sustainable development in long term and from which sources they can provide the cost-efficient energy for their economy and society [86]. For instance, before choosing solar, wind, or hydro energy as the main energy source for a given region, policy makers should have long term climatic forecast (let's say for next 30 years) for the region. If the forecasts show low precipitation in long run, the hydro power energy would not be efficient choice. On the other hand, if climatic forecast shows large number of cloudless days with high solar radiation (illumination) rate, investing in solar power plant might be a proper policy. If the historical data trend, in a region shows increase in clouds during day, policy makers will focus their policy on other recourses for long term energy supply.

As an example, let's consider the climatic variables in France. Figure 7 shows the annual average of "Evapotranspiration" measured as millimeter per day (top left), "Precipitation" measured as millimeter per month (top right), "Cloud Cover Percentage" as percentage of sky covered by clouds, daily, (bottom left) and "Temperature" measured as daily mean in degrees Celsius (bottom right). The historical data were accessed from Climate Research Unit, University of East Anglia, database [80]. These four climatic variables are selected in this example since they have known relations with renewable energy sources and have effects on performance of some electric power plants. For instance, increase in "Precipitation" could, potentially, increase the water inlet flow in hydroelectric power plants and consequently improve their performance. Increased "Evapotranspiration" and/or "Temperature", on the other hand, can increase water evaporation in dams and decrease the performance of hydroelectric power plants. An increase in "Cloud Cover Percentage" in a region, can decrease the solar radiation (illumination), since the clouds can block the solar radiation, and decrease the performance of solar power plants. As it can be seen, the "Evapotranspiration" and "Temperature" show an increasing pattern, while the "Precipitation" and "Cloud Cover Percentage" present a steady state. Increasing "Evapotranspiration" and "Temperature" may reduce hydro power plants when the precipitation is not increased. On the other hand, a high percentage of cloud cover indicates low performance in solar power plants as well. According to these historical data, assuming the recent trend will continue for long time, making policy to consider hydro power or solar energy is primary energy resources may increase energy related risks and cause energy insecurity in the future. On the other hand, since the natural gas is usually used for heating and electricity for cooling, in households, an increasing pattern in temperature suggests that in the future France will need more electricity and less natural gas in domestic section. Thus, developing more power plants to produce electricity, encouraging the use of high-performance central heating/cooling systems in buildings, and using natural (or liquid) gas for cooking purposes could be increase the energy security in future. 

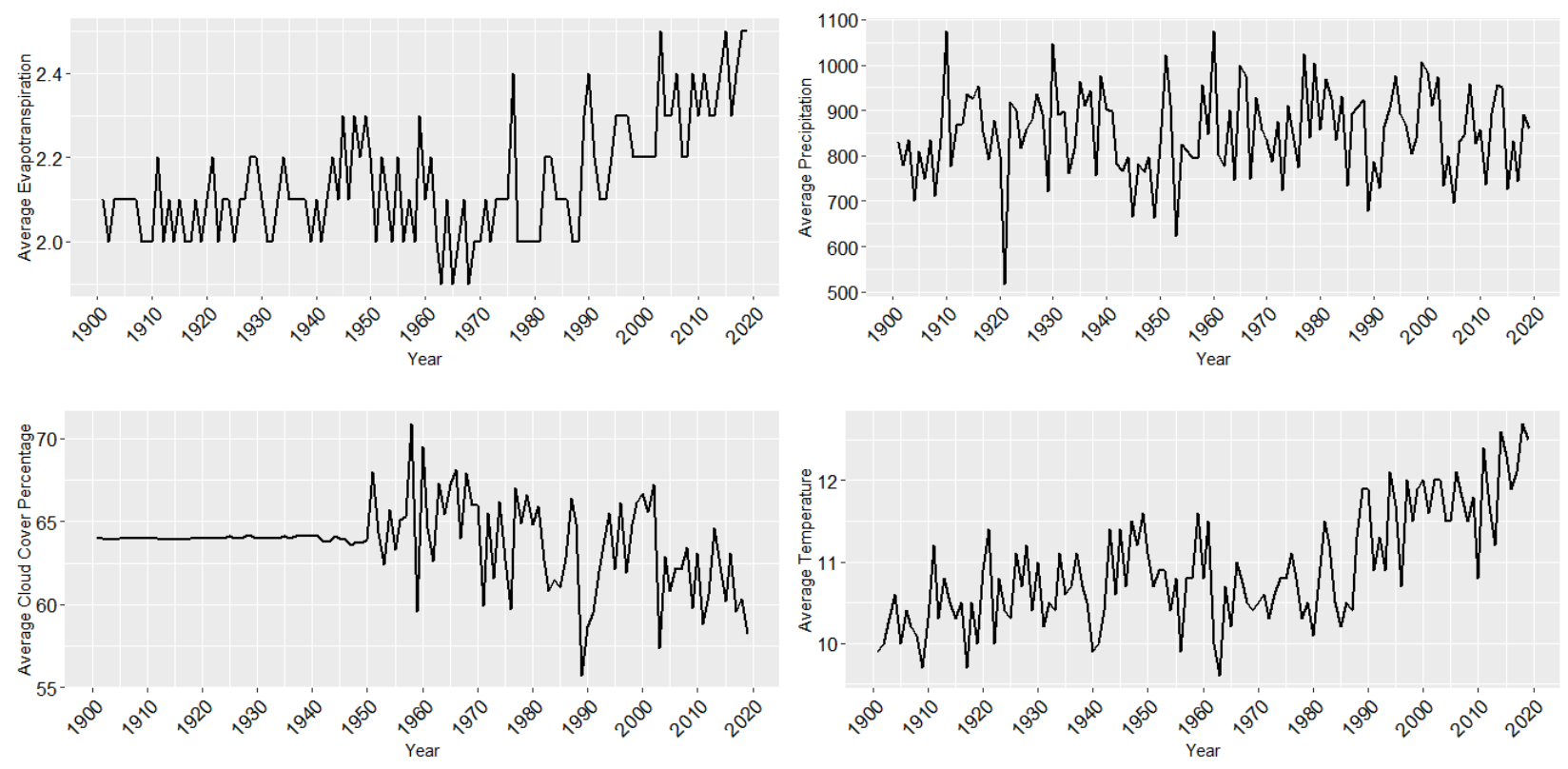

Figure 7. Annual average of climatic historical trends for France.

As mentioned earlier, there are big data solution to forecast climatic variables. There are many other variables affecting energy policies, e.g., consumer cultures, economic growth rate, environmental and ecological risk, to name a few [86]. Although using big data solutions can help policy makers to design appropriate policies to reduce energy related risks and provide sustainable energy resources for their society and economy, collecting data for big data solutions could be challenging, especially for social variables [86]. Another challenge for energy policy makers, is to measure, quantify and forecast some risk factors, like geopolitical risks and related government policies. Once all the energy risk factors and energy demand drivers are estimated, we can design the suitable energy policy for sustainable energy supply. Furthermore, once the risk factors are estimated, we can use financial instruments to hedge the energy risk and insure the economic and social results of any energy crises.

In addition to building and using big data solutions to reduce the effects of instability in the energy market, the governments and policy makers should provide private firms with access to big data resources. Using this access, private firms will be able to manage and hedge their energy risks (as discussed earlier in this section). Providing such access not only helps private firms, it can also reduce the negative impacts of an energy crisis on society and the economy.

\section{Conclusions}

This paper focusses on the leverage Big Data can provide in relation to energy security. Considering the provision of security of supply, as well as its geo-political and societal implications, Big Data has enormous potential in improving energy security as well as energy market stability. While modern energy distribution and management as well as geopolitical and technological developments almost necessitate the usage of Big Data, there is still a significant lag in the realization of certain data and technology utilization. Through the utilization of Big Data generated by peer-to-peer energy networks, balance in supply and demand can be achieved. This also allows to regulate energy shortages or to utilize energy over-productions, thus, to enhance energy security. Through the real-time matching of energy supply and demand, the consumer encounters a stabilization of energy prices. Less volatile prices, in turn, increase confidence in market and thus promote engagement in the energy market through energy suppliers and consumers. The combination of realtime supply-demand matching and ensuring of stable energy prices reduces uncertainty about energy prices and supply. Moreover, through the utilization of smart meters and 
Internet of Things, an efficient distribution of energy between providers and consumers can be achieved. An efficient distribution of energy means a higher resilience of the energy network. Through the transformation of the role of consumers towards prosumers, meaning that energy consumers are also contributing to the energy power supply, IoT allows an efficient coordination of electricity generation, which reduces the danger of a power outage. Since the utilization of new technologies and big data enhances demand detection for producers on the one hand and price transparency for consumers on the other hand, it promotes competition and thus reduces costs for energy providers as well as consumers. Furthermore, distinct energy routing allows energy load classification, including energy resource scheduling and load forecasting. Being able to forecast energy load, especially at peak hours, allows energy producers to prepare better for these peaks, and thus enhances energy security for all network participants. The above-mentioned factors lead to improved market stability in general and mitigate the risk of market disruptions. At the same time, they allow the identification of new reserves which can be extracted at cheaper costs, since a decentralized power generation lowers the cost of energy production due to a more efficient distribution of energy. Big Data also opens the door to new, profitable investment opportunities and secure investment regimes in the energy sector, as it also allows the identification of cross sectoral vulnerabilities in infrastructure and the development of new technologies to increase safety. Therefore, increased funding for network infrastructure enhances energy stability and energy security.

Another way economies can benefit from Big Data is through the utilization of weather data in order to forecast weather changes to optimize energy generation. Moreover, through collection and exchange of energy data, Big Data enables the identification of transparency risks among economies over energy resources, allocation, and utilization, which in turn reduces potential conflicts. For society, Big Data allows an increase in economic and social activity since it provides a broad inclusion possibility for energy consumers due to easier access to energy, lower energy prices, etc.

We identify and summarize the key needs for the implementation of relevant technology for data generation and collection by analyzing several use cases and highlighting the implications of Big Data usage on private companies, national economies, and society (Table 3).

The most common approach to measure energy security is through indices, which take into account dimensions such as economic conditions, environmental sustainability, and energy efficiency. The explanatory power of these indices can be significantly improved by the identification of cross relationships and patterns in endogenous as well as exogenous variables. Therefore, the utilization of Big Data can lead to significant insights.

For firms, Big Data can help combating energy supply disruptions by identifying vulnerabilities and dependencies in energy production. Moreover, it can help in handling the tradeoff between cost reduction and securing energy supply, e.g., through the utilization of smart grids.

The impact of Big Data on economies is a broader one. One of the most fundamental prerequisites for energy security is economic security. Big Data enhances the ability to understand economic causalities and how the integration of renewable resources can be conducted without causing energy supply disruptions.

While the utilization of Big Data seems mainly to be a technical or political question for firms and economies as a whole, it poses a bigger challenge for society in terms of availability, accessibility, affordability, and acceptability. On the one hand, society can benefit from Big Data generating devices such as smart meters in terms of cost reductions and automation, and thus optimal handling of energy usage, but on the other hand this raises issues such as risk of data privacy violations, fraudulent use, or even broader misconduct, such as the deliberate and targeted manipulation of consumer behavior, e.g., by identifying certain consumption behavior through surveillance and subsequent price manipulation. 
Table 3. Benefits from the usage of Big Data.

\begin{tabular}{ll}
\hline \multicolumn{1}{c}{ Usage of Big Data } & \multicolumn{1}{c}{ Benefits } \\
\hline & Prevailing balance in supply and demand \\
& Ensuring stable energy price \\
& Reduction of uncertainty in energy prices and supply \\
Impact on private companies & Contribute to efficiency in distribution of energy between providers and consumers \\
& Coordination of electricity generation \\
& Reduction of costs for energy providers and consumers \\
& Energy load classification including energy resources scheduling, load forecasting, optimal \\
& energy resources scheduling \\
& Market stability meaning little or no market disruptions \\
& Identification of new reserves to be extracted at cheaper costs \\
& Identification of profitable and secure investment regimes \\
& Identification of vulnerabilities in infrastructure and development of new technologies to \\
increase safety & Forecasting of weather changes to optimize energy generation \\
Identification of cross sectoral vulnerabilities & Real time adjustment and coordination across different energy providers \\
Contribution to definition of decision-makers rules & Contribution to good governance while identifying lack of transparency risks and potentials \\
for conflicts
\end{tabular}

Author Contributions: Conceptualization, H.H., N.K., D.K., S.U. and M.R.Y.; Investigation, H.H., N.K., D.K., S.U. and M.R.Y.; Writing-review \& editing, H.H., N.K., D.K., S.U. and M.R.Y. All authors have read and agreed to the published version of the manuscript.

Funding: This research received no external funding.

Conflicts of Interest: The authors declare no conflict of interest.

\section{Appendix A}

Table A1. Classification and comparison of authors and sources regarding their research content.

\begin{tabular}{llll}
\hline \multicolumn{1}{c}{ Impact on } & \multicolumn{1}{c}{ Field } & \multicolumn{1}{c}{ Author } & \multicolumn{1}{c}{ Content } \\
\hline $\begin{array}{l}\text { Private } \\
\text { companies }\end{array}$ & $\begin{array}{l}\text { Ambient energy } \\
\text { harvesting }\end{array}$ & Yildiz [27] & $\begin{array}{l}\text { Variety of techniques are available for } \\
\text { energy scavenging. }\end{array}$ \\
\hline & SMART RFIDs & $\begin{array}{l}\text { R. Kanan and } \\
\text { D. Petrovic [28] }\end{array}$ & $\begin{array}{l}\text { SMART RFIDs maintain and increase value across a } \\
\text { supply chain. }\end{array}$ \\
\hline Energy security & Jun et al. [13] & $\begin{array}{l}\text { Economic security dominates supply security and is } \\
\text { therefore the main driver for total security cost. }\end{array}$ \\
\hline Energy security & Cable [14] & $\begin{array}{l}\text { Understanding effects of inflation, unemployment, } \\
\text { and economic growth, on energy security. }\end{array}$ \\
\hline Privacy and Security risks & Sriramoju [15] & $\begin{array}{l}\text { Big Data mining such as risks to privacy, security } \\
\text { and complexity. }\end{array}$ \\
\hline Big Data mining & Intel [16] & $\begin{array}{l}\text { MapReduce can help in analyzing Big Data and } \\
\text { bring about business intelligence. }\end{array}$ \\
\hline Smart Grid & Hackl et al. [17] & $\begin{array}{l}\text { Analyze Sweden's largest chemical cluster, its utility } \\
\text { system and energy efficiency. }\end{array}$ \\
\hline Energy security & Jiang et al. [18] & Analyzing real-time energy consumption. \\
\hline
\end{tabular}


Table A1. Cont.

\begin{tabular}{|c|c|c|c|}
\hline Impact on & Field & Author & Content \\
\hline & Energy security & Diamantoulakis et al. [22] & $\begin{array}{l}\text { Scalability and flexibility can enable efficient } \\
\text { processing of the large data volumes. }\end{array}$ \\
\hline & Energy security & $\begin{array}{l}\text { Zhou et al. [20], } \\
\text { Vale et al. [21] }\end{array}$ & $\begin{array}{l}\text { Most important factor for energy market price } \\
\text { stability is predictive analytics. }\end{array}$ \\
\hline & IoT and security & Sen et al. [45] & $\begin{array}{l}\text { An important unmet need for security solutions is } \\
\text { context awareness. }\end{array}$ \\
\hline & Smart Grid & Bekara [48] & $\begin{array}{l}\text { Analyzes security issues and challenges for the } \\
\text { IoT-based Smart Grid. }\end{array}$ \\
\hline \multirow[t]{8}{*}{$\begin{array}{l}\text { National } \\
\text { Economies }\end{array}$} & Energy supply & Radovanovic et al. [29] & $\begin{array}{l}\text { Measurement of energy security in a global } \\
\text { economic and geopolitical sense. }\end{array}$ \\
\hline & Energy security & Le and Nguyen [32] & Energy security enhances economic growth. \\
\hline & Economic security & IMF [33] & $\begin{array}{l}\text { Economic security contribute to the rise of } \\
\text { private investment. }\end{array}$ \\
\hline & Energy security & Bohi and Toman [97] & $\begin{array}{l}\text { How does energy security changed over time from } \\
\text { the focus on military preparedness. }\end{array}$ \\
\hline & Energy security & Cherp et al. [30] & $\begin{array}{l}\text { Provides overview of significance of global energy } \\
\text { security issues. }\end{array}$ \\
\hline & Energy security & $\begin{array}{l}\text { McDowell and } \\
\text { Goldstein [34] }\end{array}$ & Digital object architecture is important for IoT. \\
\hline & Cybersecurity of the IoT & Carr and Lesniewska [35] & $\begin{array}{l}\text { Global climate governance is an early model of a } \\
\text { onsensual rules-based approach to tackle } \\
\text { cybersecurity issues of the IoT. }\end{array}$ \\
\hline & Energy supply & Hossein et al. [47] & $\begin{array}{l}\text { Integration of renewable energy and optimization of } \\
\text { energy use are key enablers of sustainable energy } \\
\text { transitions and mitigating climate change. }\end{array}$ \\
\hline \multirow[t]{10}{*}{ Society } & Fog Computing & Bonomi et al. [41] & $\begin{array}{l}\text { IoT requires mobility support and geo-distribution } \\
\text { in addition to location awareness and low latency. }\end{array}$ \\
\hline & Economic security & $\begin{array}{l}\text { Houseknecht and } \\
\text { Abdel Aal [36] }\end{array}$ & $\begin{array}{l}\text { Shifts from informal to formal arrangements for } \\
\text { economic security leads to change in the structural } \\
\text { features of the family. }\end{array}$ \\
\hline & Smart technologies & Liu [37] & $\begin{array}{l}\text { Smart grid enables both utility providers and } \\
\text { customers to transfer, monitor, predict, and manage } \\
\text { energy usage effectively and costly. }\end{array}$ \\
\hline & Privacy risks & Zhang [40] & $\begin{array}{l}\text { Improve privacy protection legal mechanism, } \\
\text { establish a privacy protection agency, improve of } \\
\text { people's awareness, quality of data. }\end{array}$ \\
\hline & Privacy risks & Liu [37] & $\begin{array}{l}\text { Wireless sensor networks raise new } \\
\text { security challenges. }\end{array}$ \\
\hline & Communication & Khan et al. [42] & $\begin{array}{l}\text { Communication will change from human-to-human } \\
\text { to human-to-machine. }\end{array}$ \\
\hline & Edge computing & Shi et al. [43] & $\begin{array}{l}\text { Improves response time, battery life, bandwidth cost } \\
\text { saving, data safety and privacy. }\end{array}$ \\
\hline & Smart technologies & Marres [39] & $\begin{array}{l}\text { Digital technologies create weak deterministic ideas } \\
\text { about principal drivers of social change. }\end{array}$ \\
\hline & Privacy risks & Tawalbeh et al. [46] & $\begin{array}{l}\text { Identify different security and privacy issue of } \\
\text { IoT-based systems. }\end{array}$ \\
\hline & Device security & Trappe et al. [49] & $\begin{array}{l}\text { IoT's future will rely on our ability to adequately } \\
\text { secure hard-to-secure, resource-sparse devices. }\end{array}$ \\
\hline
\end{tabular}




\section{References}

1. Energy Security-Areas of Work-IEA. Available online: https://www.iea.org/areas-of-work/ensuring-energy-security (accessed on 20 August 2020).

2. US Energy Association. Available online: https://usea.org/about-usea (accessed on 21 August 2020).

3. Kruyt, B.; van Vuuren, D.P.; de Vries, H.J.K.; Groenenberg, H. Indicators for energy security. Energy Policy 2009, 37, $2166-2181$. [CrossRef]

4. Sovacool, B.K.; Mukherjee, I. Conceptualizing and measuring energy security: A synthesized approach. Energy 2011, 36, 5343-5355. [CrossRef]

5. Ang, B.W.; Choong, W.L.; Ng, T.S. Energy security: Definitions, dimensions and indexes. Renew. Sustain. Energy Rev. 2015, 42, 1077-1093. [CrossRef]

6. Chalvatzis, K.; Hooper, E. Energy security vs. climate change: Theoretical framework development and experience in selected EU electricity markets. Renew. Sustain. Energy Rev. 2009, 13, 2703-2709. [CrossRef]

7. Yergin, D. Ensuring energy security. Foreign Aff. 2006, 85, 69-82. [CrossRef]

8. Mueller-Kraenner, S. Energy Security: Re-Measuring the World; Earthscan: London, UK, 2008.

9. Chester, L. Conceptualisingenergy security and making explicit its polysemic nature. Energy Policy 2010, 38, 887-895. [CrossRef]

10. Gellings, C.W.; Samotyj, M.; Howe, B. The future's smart delivery system [electric power supply]. IEEE Power Energy Mag. 2004, 2, 40-48. [CrossRef]

11. Goertz, G. Social Science Concepts: A User's Guide; Princeton University Press: Princeton, NJ, USA, 2006.

12. Gerring, J. What makes a concept good? A criterial framework for understanding concept formation in the social sciences. Polity 1999, 31, 357-393. [CrossRef]

13. Jun, E.; Kim, W.; Chang, S.H. The analysis of security cost for different energy sources. Appl. Energy 2009, 86, 1894-1901. [CrossRef]

14. Cable, V. What is international economic security? Int. Aff. 1995, 71, 305-324. [CrossRef]

15. Sriramoju, S.B. Opportunities and security implications of bid data mining. Int. J. Res. Sci. Eng. 2017, 3, 44-58. Available online: https://www.researchgate.net/publication/321097052_OPPORTUNITIES_AND_SECURITY_IMPLICATIONS_OF_BIG_ DATA_MINING (accessed on 12 December 2021).

16. Intel IT Center. Distributed Data Mining and Big Data; Intel: Santa Clara, CA, USA, 2012; Available online: https: //www.intel.com/content/dam/www/public/us/en/documents/white-papers/distributed-data-mining-paper.pdf (accessed on 12 December 2021).

17. Hackl, R.; Andersson, E.; Harvey, S. Targeting for energy efficiency and improved energy collaboration between different companies using total site analysis (TSA). Energy 2011, 36, 4609-4615. [CrossRef]

18. Jiang, H.; Wang, K.; Wang, Y.; Gao, M.; Zhang, Y. Energy big data: A survey. IEEE Access 2016, 4, 3844-3861. [CrossRef]

19. Zhou, K.; Fu, C.; Yang, S. Big data driven smart energy management: From big data to big insights. Renew. Sustain. Energy Rev. 2016, 56, 215-225. [CrossRef]

20. Zhou, K.; Yang, S.; Shen, C. A review of electric load classification in smart grid environment. Renew. Sustain. Energy Rev. 2013, 24, 103-110. [CrossRef]

21. Vale, Z.; Morais, H.; Ramos, S.; Soares, J.; Faria, P. Using data mining techniques to support DR programs definition in smart grids. In Proceedings of the IEEE Power and Energy Society General Meeting, Detroit, MI, USA, 24-28 July 2011; pp. 1-8. [CrossRef]

22. Diamantoulakis, P.D.; Kapinas, V.M.; Karagiannidis, G.K. Big data analytics for dynamic energy management in smart grids. Big Data Res. 2015, 2, 94-101. [CrossRef]

23. Research \& Advisory Group. Break-Even Oil Prices: The Risks of an Extended Price War for OPEC-Plus; Energy Intelligence: New York, NY, USA, 2020; Available online: http:/ / www2.energyintel.com/BreakEvenOilPricesT (accessed on 4 October 2020).

24. Regulation (EU) 2015/757 of the European Parliament and of the Council of 29 April 2015 on the Monitoring, Reporting and Verification of Carbon Dioxide Emissions from Maritime Transport, and Amending Directive 2009/16/EC. Off. J. Eur. Union 2015, L123/55. Available online: https:/ / eur-lex.europa.eu/legal-content/EN/TXT/PDF/?uri=CELEX:32015R0757\&from=EL (accessed on 20 August 2020).

25. Taleb, N. The Black Swan: The Impact of the Highly Improbable; Penguin Press: London, UK, 2008.

26. TradeLens: Digital Global Supply Chain. Available online: https://www.tradelens.com/ (accessed on 4 October 2020).

27. Yildiz, F. Potential ambient energy-harvesting sources and techniques. J. Technol. Stud. 2009, 35, 40-48. [CrossRef]

28. Kanan, R.; Petrovic, D. Rapid prototyping system for RFID sensing applications. In Proceedings of the Smart SysTech 2012, European Conference on Smart Objects, Systems and Technologies, Osnabrueck, Germany, 12-13 June 2012; pp. 1-7.

29. Radovanović, M.; Filipović, S.; Golušin, V. Geo-economic approach to energy security measurement-principal component analysis. Renew. Sustain. Energy Rev. 2018, 82, 1691-1700. [CrossRef]

30. Cherp, A.; Adenikinju, A.; Goldthau, A.; Hernandez, F.; Hughes, L.; Jansen, J.; Jewell, J.; Olshanskaya, M.; Soares de Oliveira, R.; Sovacool, B.; et al. Chapter 5: Energy and security. In Global Energy Assessment: Toward a Sustainable Future; GEA Writing Team, Ed.; Cambridge University Press and IIASA: Cambridge, UK, 2012; pp. 325-384. Available online: http://pure.iiasa.ac.at/id/eprint/ 10062/ (accessed on 4 October 2020).

31. International Atomic Energy Agency. Financing of New Nuclear Power Plants, Nuclear Energy Series No. NG-T-4.2; IAEA: Vienna, Austria, 2008. 
32. Le, T.-H.; Nguyen, C.P. Is energy security a driver for economic growth? Evidence from a global sample. Energy Policy 2019, 129, 436-451. [CrossRef]

33. Poirson, H. Economic Security, Private Investment, and Growth in Developing Countries; Working paper WP/98/4; International Monetary Fund: Washington, DC, USA, 1998; Available online: https://www.imf.org/external/pubs/ft/wp/wp9804.pdf (accessed on 4 October 2020).

34. McDowell, R.M.; Goldstein, G.M. The authoritarian internet power grab. Wall Street J. 2016. Available online: www.wsj.com/ articles / the-authoritarian-Internet-power-grab-1477436573 (accessed on 12 December 2021).

35. Carr, M.; Lesniewska, F. Internet of things, cybersecurity and governing wicked problems: Learning from climate change governance. Int. Relat. 2020, 34, 391-412. [CrossRef]

36. Houseknecht, S.K.; Abdel Aal, M. Forms of economic security and the family. J. Comp. Fam. Stud. 1998, 29, 429-449. [CrossRef]

37. Liu, Y. Wireless sensor network applications in smart grid: Recent trends and challenges. Int. J. Distrib. Sens. Netw. 2012, 8, 492819. [CrossRef]

38. Potential Benefits to Society Through Smart Metering Initiatives. Available online: https://www.smart-energy.com/regionalnews/north-america / potential-benefits-to-society-through-smart-metering-initiatives / (accessed on 23 May 2020).

39. Marres, N. On some uses and abuses of topology in the social analysis of technology (or the problem with smart meters). Theory Cult. Soc. 2012, 29, 288-310. [CrossRef]

40. Zhang, D. Big data security and privacy protection. In Proceedings of the 8th International Conference on Management and Computer Science, Shenyang, China, 10-12 August 2018; pp. 275-278. [CrossRef]

41. Flavio, B.; Rodolfo, M.; Jiang, Z.; Sateesh, A. Fog computing and its role in the internet of things. In Proceedings of the First Edition of the MCC Workshop on Mobile Cloud Computing (MCC '12), Association for Computing Machinery, New York, NY, USA, 13-16 August 2012. [CrossRef]

42. Khan, R.; Khan, S.U.; Zaheer, R.; Khan, S. Future internet: The internet of things architecture, possible applications and key challenges, 2012. In Proceedings of the 10th International Conference on Frontiers of Information Technology, Islamabad, Pakistan, 17-19 December 2012; pp. 257-260. [CrossRef]

43. Shi, W.; Cao, J.; Zhang, Q.; Li, Y.; Xu, L. Edge computing: Vision and challenges. IEEE Internet Things J. 2016, 3, 637-646. [CrossRef]

44. ETSI European Standard, CYBER.; Cyber Security for Consumer Internet of Things: Baseline Requirements, ETSI EN 303645 V2.1.1 (2020-06), June 2020. Available online: https:/ /www.etsi.org/deliver/etsi_en/303600_303699/303645/02.01.01_60/en_30 3645v020101p.pdf (accessed on 12 December 2021).

45. Sen, S.; Koo, J.; Bagchi, S. TRIFECTA: Security, energy efficiency, and communication capacity comparison for wireless IoT devices. IEEE Internet Comput. 2018, 22, 74-81. [CrossRef]

46. Tawalbeh, L.; Muheidat, F.; Tawalbeh, M.; Quwaider, M. IoT privacy and security: Challenges and solutions. Appl. Sci. 2020, 10, 4102. [CrossRef]

47. Hossein Motlagh, N.; Mohammadrezaei, M.; Hunt, J.; Zakeri, B. Internet of Things (IoT) and the energy sector. Energies 2020, 13, 494. [CrossRef]

48. Bekara, C. Security issues and challenges for the IoT-based smart grid. Procedia Comput. Sci. 2014, 34, 532-537. [CrossRef]

49. Trappe, W.; Howard, R.; Moore, R.S. Low-Energy security: Limits and opportunities in the Internet of Things. IEEE Secur. Privacy 2015, 13, 14-21. [CrossRef]

50. Chen, Q.; Liu, N.; Wang, C.; Zhang, J. Optimal power utilizing strategy for PV-based EV charging stations considering Real-time price. In Proceedings of the 2014 IEEE Conference and Expo Transportation Electrification Asia-Pacific (ITEC Asia-Pacific), Beijing, China, 31 August-3 September 2014; pp. 1-6.

51. Pazouki, S.; Mohsenzadeh, A.; Ardalan, S.; Haghifam, M.-R. Simultaneous Planning of PEV Charging Stations and DGs Considering Financial, Technical, and Environmental Effects. Can. J. Electr. Comput. Eng. 2015, 38, 238-245. [CrossRef]

52. Pazouki, S.; Mohsenzadeh, A.; Haghifam, M.-R.; Ardalan, S. Simultaneous Allocation of Charging Stations and Capacitors in Distribution Networks Improving Voltage and Power Loss. Can. J. Electr. Comput. Eng. 2015, 38, 100-105. [CrossRef]

53. Ghasempour, A. Internet of Things in smart grid: Architecture, applications, services, key technologies, and challenges. Inventions 2019, 4, 22. [CrossRef]

54. NIST Releases Final Version of Smart Grid Framework. Available online: https://www.nist.gov/smartgrid/upload/NIST-SP-11 08r3.pdf (accessed on 16 January 2019).

55. Mouftah, H.T.; Erol-Kantarci, M.; Rehmani, M.H. Communication architectures and technologies for advanced smart grid services. In Transportation and Power Grid in Smart Cities: Communication Networks and Services, 1st ed.; Mouftah, H.T., Erol-Kantarci, M., Rehmani, M.H., Eds.; Wiley: Hoboken, NJ, USA, 2019; pp. 217-245.

56. Zhao, Z.; Chen, G. An overview of cyber security for smart grid. In Proceedings of the 2018 IEEE 27th International Symposium on Industrial Electronics, Cairns, Australia, 13-15 June 2018; pp. 1127-1131.

57. Refaat, S.S.; Abu-Rub, H.; Trabelsi, M.; Mohamed, A. Reliability evaluation of smart grid system with large penetration of distributed energy resources. In Proceedings of the 2018 IEEE International Conference on Industrial Technology (ICIT), Lyon, France, 20-22 February 2018; pp. 1279-1284.

58. Refaat, S.S.; Mohamed, A.; Kakosimos, P. Self-healing control strategy; challenges and opportunities for distribution systems in smart grid. In Proceedings of the 2018 IEEE 12th International Conference on Compatibility, Power Electronics and Power Engineering (CPE-POWERENG 2018), Doha, Qatar, 10-12 April 2018; pp. 1-6. 
59. Jarvis, R.; Moses, P. Smart grid congestion caused by plug-in electric vehicle charging. In Proceedings of the 2019 IEEE Texas Power and Energy Conference (TPEC), College Station, TX, USA, 7-8 February 2019; pp. 1-5.

60. Rafiei, S.; Bakhshai, A. A review on energy efficiency optimization in Smart Grid. In Proceedings of the 38th Annual Conference on IEEE Industrial Electronics Society, Montreal, QC, Canada, 25-28 October 2012; pp. 5916-5919.

61. Akaber, P.; Moussa, B.; Debbabi, M.; Assi, C. Automated post-failure service restoration in smart grid through network reconfiguration in the presence of energy storage systems. IEEE Syst. J. 2019, 1-10. [CrossRef]

62. Qi, F.; Yu, P.; Chen, B.; Li, W.; Zhang, Q.; Jin, D.; Zhang, G.; Wang, Y. Optimal planning of smart grid communication network for interregional wide-area monitoring protection and control system. In Proceedings of the 2018 IEEE International Conference on Energy Internet (ICEI), Beijing, China, 21-25 May 2018; pp. 190-195.

63. Ghasempour, A. Optimum packet service and arrival rates in advanced metering infrastructure architecture of smart grid. In Proceedings of the 2016 IEEE Green Technologies Conference (IEEE GreenTech 2016), Kansas City, MO, USA, 6-8 April 2016; pp. 1-5.

64. Ghasempour, A.; Gunther, J.H. Finding the optimal number of aggregators in machine-to-machine advanced metering infrastructure architecture of smart grid based on cost, delay, and energy consumption. In Proceedings of the 2016 13th IEEE Annual Consumer Communications \& Networking Conference (IEEE CCNC 2016), Las Vegas, NV, USA, 9-12 January 2016; pp. 960-963.

65. Ghasempour, A. Optimized scalable decentralized hybrid advanced metering infrastructure for smart grid. In Proceedings of the 2015 IEEE International Conference on Smart Grid Communications (IEEE SmartGridComm 2015), Miami, FL, USA, 2-5 November 2015; pp. 223-228.

66. Aileni, R.M. Healthcare predictive model based on big data fusion from biomedical sensors. In Proceedings of the Conference eLearning and Software for Education eLSE, Bucharest, Romania, 21-22 April 2016; Carol I" National Defense University Publishing House: Bucharest, Romania, 2016; pp. 328-333.

67. Plageras, A.P.; Psannis, K.E.; Stergiou, C.; Wang, H.; Gupta, B.B. Efficient IoT-based sensor big data collection-processing and analysis in smart buildings. Future Gener. Comput. Syst. 2018, 82, 349-357. [CrossRef]

68. Huang, Y.; Chen, Z.-X.; Yu, T.; Huang, X.-Z.; Gu, X.-F. Agricultural remote sensing big data: Management and applications. J. Integr. Agric. 2018, 17, 1915-1931. [CrossRef]

69. Jiang, P.; Winkley, J.; Zhao, C.; Munnoch, R.; Min, G.; Yang, L.T. An intelligent information forwarder for healthcare big data systems with distributed wearable sensors. IEEE Syst. J. 2014, 10, 1147-1159. [CrossRef]

70. Zaslavsky, A.; Perera, C.; Georgakopoulos, D. Sensing as a service and big data. arXiv 2013, arXiv:1301.0159.

71. Westbrook, P. Big data on the horizon from a new generation of distributed optical fiber sensors. APL Photonics 2020, 5, 020401. [CrossRef]

72. Tang, B.; Chen, Z.; Hefferman, G.; Pei, S.; Wei, T.; He, H.; Yang, Q. Incorporating intelligence in fog computing for big data analysis in smart cities. IEEE Trans. Ind. Inform. 2017, 13, 2140-2150. [CrossRef]

73. Zhang, Y.; Ma, S.; Yang, H.; Lv, J.; Liu, Y. A big data driven analytical framework for energy-intensive manufacturing industries. J. Clean. Prod. 2018, 197, 57-72. [CrossRef]

74. Syed, A.; Gillela, K.; Venugopal, C. The future revolution on big data. Future 2013, 2, 2446-2451.

75. Dai, H.-N.; Wang, H.; Xu, G.; Wan, J.; Imran, M. Big data analytics for manufacturing internet of things: Opportunities, challenges and enabling technologies. Enterp. Inf. Syst. 2020, 14, 1279-1303. [CrossRef]

76. Ahmad, I.; Ayub, A.; Kano, M.; Cheema, I.I. Gray-box soft sensors in process industry: Current practice, and future prospects in era of big data. Processes 2020, 8, 243. [CrossRef]

77. Lee, C.-H.; Yang, H.-C.; Lin, S.-J. Incorporating big data and Social Sensors in a Novel Early Warning System of Dengue Outbreaks. In Proceedings of the 2015 IEEE/ACM International Conference on Advances in Social Networks Analysis and Mining, Paris, France, 25-28 August 2015; pp. 1428-1433.

78. Bakytbekov, A.; Nguyen, T.Q.; Li, W.; Cottrill, A.L.; Zhang, G.; Strano, M.S.; Salama, K.N.; Shamim, A. Multi-source ambient energy harvester based on RF and thermal energy: Design, testing, and IoT application. Energy Sci. Eng. 2020, 8, $3883-3897$. [CrossRef]

79. Data and Statistics. Available online: https://www.iea.org/data-and-statistics?country=FRANCE\&fuel=Energy \%20supply\& indicator=TPESbySource (accessed on 5 November 2020).

80. Climatic Research Unit: Data: High-Resolution Datasets: CRUTS 4.04: CRU CY 4.04. Available online: https://crudata.uea.ac uk/cru/data/hrg/cru_ts_4.04/crucy.2004161557.v4.04/countries/ (accessed on 30 September 2020).

81. Database-Eurostat. Available online: https://ec.europa.eu/eurostat/web/energy/data/database?p_p_id=NavTreeportletprod_ WAR_NavTreeportletprod_INSTANCE_QAMy7Pe6HwI1\&p_p_lifecycle=0\&p_p_state=normal\&p_p_mode=view\&p_p_col_ id=column-2\&p_p_col_count=1 (accessed on 30 September 2020).

82. CAC Oil \& Gas Historical Rates (FROG). Available online: https:/ /www.investing.com/indices/cac-oil---gas-historical-data (accessed on 30 September 2020).

83. Wieczorek-Kosmala, M. Weather risk management in energy sector: The Polish case. Energies 2020, 13, 945. [CrossRef]

84. Hassani, H.; Huang, X.; Silva, E. Big data and climate change. BIG DATA and Cogn. Comput. 2019, 3, 12. [CrossRef]

85. Medina, H.; Tian, D.; Marin, F.R.; Chirico, G.B. Comparing GEFS, ECMWF, and post processing methods for ensemble precipitation forecasts over Brazil. J. Hydrometeorol. 2019, 20, 773-790. [CrossRef] 
86. Hassani, H.; Yeganegi, M.R.; Beneki, C.; Unger, S.; Moradghaffari, M. Big data and energy poverty alleviation. Big Data Cogn. Comput. 2019, 3, 50. [CrossRef]

87. Del Real, A.J.; Dorado, F.; Durán, J. Energy demand forecasting using deep learning: Applications for the French grid. Energies 2020, 13, 2242. [CrossRef]

88. Bhattacharyya, S.C.; Timilsina, G.R. Energy Demand Models for Policy Formulation, a Comparative Study of Energy Demand Models; The World Bank Development Research Group Environment and Energy Team: Washington, DC, USA, 2009; Available online: https:/ / openknowledge.worldbank.org/bitstream/handle/10986/4061/WPS4866.pdf (accessed on 10 November 2020).

89. Amjady, N.; Hemmati, M. Energy price forecasting-problems and proposals for such predictions. IEEE Power Energy Mag. 2006, 4, 20-29. [CrossRef]

90. Weron, R. Electricity price forecasting: A review of the state-of-the-art with a look into the future. Int. J. Forecast. 2014, 1030-1081. [CrossRef]

91. Andriosopoulos, D.; Doumpos, M.; Pardalos, P.M.; Zopounidis, C. Computational approaches and data analytics in financial services: A literature review. J. Oper. Res. Soc. 2019, 70, 1581-1599. [CrossRef]

92. Hassani, H.; Beneki, C.; Unger, S.; Mazinani, M.T.; Yeganegi, M.R. Text mining in big data analytics. Big Data Cogn. Comput. 2020, 4, 1. [CrossRef]

93. Cerchiello, P.; Giudici, P. Big data analysis for financial risk management. J. Big Data 2016, 3, 18. [CrossRef]

94. Kou, G.; Chao, X.; Peng, Y.; Alsaadi, F.E.; Herrera-Viedma, E. Machine learning methods for systemic risk analysis in financial sectors. Technol. Econ. Dev. Econ. 2019, 25, 716-742. [CrossRef]

95. Chen, A.S.; Leung, M.T.; Pan, S.; Chou, C.-Y. Financial hedging in energy market by cross-learning machines. Neural Comput. Applic. 2020, 32, 10321-10335. [CrossRef]

96. Lie, E.A.; Gullaksen, M.F. Using Machine Learning to Improve Hedging of Power Prices in the Nordic Market: A Study of How Predictions of the Nordic System Price can be Used for Norwegian Hydropower Producer's Hedging Strategies. Master's Thesis, Economics and Business Administration, Norwegian School of Economics, Bergen, Norway, 2019. Available online: https: / / openaccess.nhh.no/nhh-xmlui/bitstream/handle/11250/2644902/masterthesis.pdf?sequence=1 (accessed on 25 November 2020).

97. Bohi, T.; Toman, M. The Economics of Energy Security; Kluwer Academic Publishers: Boston, MA, USA, 1996. [CrossRef] 